\title{
Estimation of Fouling Model Parameters for Shell Side and Tube Side of Crude Oil Heat Exchangers Using Data Reconciliation and Parameter Estimation
}

DOI:

10.1021/acs.iecr.9b00457

\section{Document Version}

Accepted author manuscript

Link to publication record in Manchester Research Explorer

Citation for published version (APA):

Loyola Fuentes, J. (2019). Estimation of Fouling Model Parameters for Shell Side and Tube Side of Crude Oil Heat Exchangers Using Data Reconciliation and Parameter Estimation. Industrial \& Engineering Chemistry Research. https://doi.org/10.1021/acs.iecr.9b00457

\section{Published in:}

Industrial \& Engineering Chemistry Research

\section{Citing this paper}

Please note that where the full-text provided on Manchester Research Explorer is the Author Accepted Manuscript or Proof version this may differ from the final Published version. If citing, it is advised that you check and use the publisher's definitive version.

\section{General rights}

Copyright and moral rights for the publications made accessible in the Research Explorer are retained by the authors and/or other copyright owners and it is a condition of accessing publications that users recognise and abide by the legal requirements associated with these rights.

\section{Takedown policy}

If you believe that this document breaches copyright please refer to the University of Manchester's Takedown Procedures [http://man.ac.uk/04Y6Bo] or contact uml.scholarlycommunications@manchester.ac.uk providing relevant details, so we can investigate your claim.

\section{OPEN ACCESS}




\title{
Estimation of Fouling Model Parameters for Shell-
}

\author{
side and Tube-side of Crude Oil Heat Exchangers
}

\section{Using Data Reconciliation and Parameter Estimation}

\author{
José Loyola-Fuentes *, Megan Jobson, Robin Smith
}

Centre for Process Integration, School of Chemical Engineering and Analytical Science,

The University of Manchester, M13 9PL, UK

\begin{abstract}
Fouling modelling in crude oil heat exchangers is of great importance industrially. Current approaches use empirical or semi-empirical approaches, where fouling rate models are necessary. A series of parameters need to be determined, which directly depend on the nature and type of crude oil. These parameters can be estimated either by using laboratory experiments or, in principle, by measured process-data. This work focuses on the estimation of fouling rate model parameters using measured-data. An optimization-based data reconciliation approach, which accounts for random and gross errors, is integrated with a parameter-fitting algorithm. The methodology is tested in a case study, where a multi-pass heat exchanger is simulated. The effects of measurement error and fouling deposition on both sides are addressed. The fouling resistance is predicted and compared with the simulated data, showing good agreement as well as providing evidence for a successful separation of fouling resistances on both sides of a heat exchanger. Finally, studies are presented to show the isolation process for the minimum gross error magnitude, for different gross error locations.
\end{abstract}

Keywords: Gross error detection, Measured-data, Simulation, Optimization.

\footnotetext{
*Corresponding author's email address: jose.loyolafuentes@manchester.ac.uk
} 


\section{Introduction}

Ever since heat exchangers were first implemented, deposition of unwanted material known as fouling has been recognized as a major problem ${ }^{1}$. The effect of fouling on thermal and hydraulic performance is known to be greatly significant if not properly addressed. The formation of an extra thermo-physical layer across the heat transfer area decreases the flow of heat across both sides of shell-and-tube heat exchangers, and increases the pressure drop through the equipment ${ }^{2}$. The fouling layer has also a major impact on energy consumption, maintenance and capital costs. For example, in the United Kingdom, the total cost associated with fouling has reached values close to U.S.\$26.0 million per year, for a throughput basis of 100,000 barrels per day ${ }^{3}$.

Fouling deposition is studied by analyzing its dynamic change through a heat exchanger. This change is commonly known as the fouling rate. Several variables affect this value. Physical properties such as viscosity and density, as well as stream temperature and velocity, usually set the build-up of fouling layers, which grow by means of different mechanisms. To date, five major fouling mechanisms have been reported in the literature, as described by Epstein ${ }^{4}$. In the case of crude oil refineries, a combination of several of these mechanisms, such as particulate, chemical reaction and crystallization fouling are frequently encountered on each side of a heat exchanger ${ }^{5}$, with chemical reaction fouling being the most common mechanism for high temperature operations in crude oil heat exchangers. Field-based and experimental studies have been carried out to understand the fouling phenomena, and to establish standards and mathematical models for considering fouling in the design, optimization and retrofit of heat transfer processes.

Remarkable advances have been achieved from several studies regarding experimental and mathematical characterization of the fouling deposition process ${ }^{6}$. Stirred vessels and recirculation systems have been commonly used for analyzing crude oil fouling behavior ${ }^{7}$. As a result of these studies, several fouling models and concepts relevant to crude oil have been developed. The foundation for each model relies on the physical concept of fouling rate, which is defined as the competition between deposition and removal rates ${ }^{8}$. Note that the concept "removal" is used in accordance with the original definition proposed by Kern and Seaton ${ }^{8}$; however, later studies have shown that in the context of crude oil pre-heat trains, there is a lack of evidence regarding operating conditions that set off the occurrence of fouling deposition ${ }^{9}$. For design and optimization applications, the concept of a fouling threshold for chemical reaction 
models has proven to be of great significance and its study has increased over the past decade. The fouling threshold defines a geometrical locus (consisting of wall temperature and surface wall shear stress) below which fouling deposition is not expected to occur. The main disadvantage of these models is that they are originated from empirical or semi-empirical studies, requiring a set of parameters that are specific to each type of crude oil and process conditions such as stream velocity and temperature. Therefore, any change in fluids in a crude oil heat exchanger will have an effect in the values of these parameters. Changes in the dominant fouling mechanism are also expected if operating conditions change significantly.

If a certain set of fouling model parameters is to be found, specific information regarding the dynamic increase in fouling resistance is needed. These measurements can be taken from laboratory tests or via measurement instruments on specific locations of the plant. Sampling and experimental testing are used whenever fouling deposition is to be studied, independent from any other significant variable such as heat flux, fluid temperature and fluid velocities. Such controlled conditions allow for a better understanding of the fundamental basis of fouling deposition. However, laboratory-based studies do not represent realistically what happens during plant operation. On the other hand, field-data can be used for determining fouling models, as they reflect the intrinsic variability of the plant, but only when each measurement instrument is properly calibrated. In other words, well-maintained instruments improve the quality of measured data, which can be disrupted by miscalibrations, equipment failures and events that could perturb the measurements.

When working with operational data and measurement error, numerous methods are available for addressing the consequences of such measurement errors. In this work, data reconciliation is used, as it is the most suitable approach. Data reconciliation exploits the existing redundancy among operational variables in order to determine the best set of measurement magnitudes that could satisfy specific process constraints ${ }^{10}$. Data reconciliation can be integrated with the identification of faulty instruments through gross error detection techniques ${ }^{11}$. These techniques are based on a combination of statistical tests and optimization problems, which result in nonbiased solutions for optimal magnitudes of measurements and simultaneously, presence, location (measurements containing such gross errors) and numerical values for any gross error in one or more measurements. Special attention needs to be placed on the effect of gross errors in the overall measurement adjustments (that is, the change in a measurement's value after 
reconciliation), also known as the smearing effect ${ }^{12}$. The mitigation (reduction) of measurement error using data reconciliation can be exploited when estimating fouling model parameters, as the reconciled data provides un-biased inputs.

The majority of current fouling rate models have been developed and implemented only on the tube-side of a heat exchanger, neglecting the effect of fouling deposition on the shell-side. Although fouling on the shell-side of heat exchangers is often less important, it can be a significant issue. Specific cases have been reported, where shell-side fouling dominates over tube-side deposition, as shown in Diaz-Bejarano and Coletti ${ }^{13}$. In their work, a local-based dynamic model for a crude oil heat exchanger including shell-side and tube-side fouling was applied to assess its thermo-hydraulic performance. Threshold fouling models were considered for both sides of the heat exchanger, where slight modifications were employed for the shell-side fouling modelling, based on the tube-side fouling rate model proposed by Ebert and Panchal ${ }^{14}$. The results showed good agreement between the model and collected data, confirming that shellside fouling can be significant. However, detailed analyses concerning flow patterns and fouling mechanisms are still under study. Subsequently, any attempt for separating both fouling contributions is at the moment, simplified but still relevant.

The calculation of fouling model parameters has been mostly studied in laboratory experiments, rather than addressing this task using operational data. One of the reasons for this is the current lack of methods for improving the reliability of measured data when fouling occurs, that is, how accurate these measurements are when compared to a validated plant model ${ }^{5}$. Another reason is the complexity associated with building a representative set of data that can include the effect of fouling in process variables, such as temperature. In order to reduce the propagation of measurement error when calculating overall and local heat transfer coefficients, the correlations proposed by Wang et al. ${ }^{15}$ are used. In their work, a simple and reliable model for evaluating the performance of shell-and-tube heat exchangers was proposed. Straightforward correlations were developed for shell-side and tube-side local heat transfer coefficients and pressure drops. Results were compared with validated commercial software such as $\mathrm{HTRI}^{\circledR}$ and HEXTRAN $^{\circledR}$.

Comparisons among laboratory, pilot plant and plant data were done by Yeap et al. ${ }^{16}$. Different fouling models were regressed against these sets of data, and a thermo-hydraulic analysis was carried out to determine the most suitable fouling rate model for different scenarios. 
This study focuses mainly on chemical reaction fouling on the tube side, as it is the dominant mechanism in high-temperature operations, such as the hot end of a crude oil pre-heat train. A threshold fouling model was used and no data reconciliation was implemented. The methodology proved to be useful for encouraging further research regarding fouling deposition and modelling development.

Local temperature variations across the tube side of a heat exchanger are presented by Polley et al. ${ }^{17}$. A short-cut model was developed, where an overall fouling resistance was obtained by integrating the fouling rate model with respect to temperature. Temperature variations as a function of tube length were modelled by assuming a linear distribution through the tube-side. Data reconciliation was considered, but no details about which algorithm was selected were given. Gross error detection was not mentioned. Acceptable agreement was reported when comparing field-data with predictions of the model proposed by Polley et al ${ }^{18}$.

A more rigorous analysis was presented by Coletti and Macchietto ${ }^{19}$, where a dynamic heat exchanger model including fouling deposition and aging of the fouling layer was proposed. The simulation strategy accounts for local variations in temperature, flow velocity and physical properties, and operational data (flow rate and temperature) are used as inputs. These data are pre-filtered via statistical calculations, without being considered by the authors as a data reconciliation method. The model outputs were compared against the filtered data, where several outcomes were highlighted. Outlet conditions (temperatures for hot and cold streams) were used as indicators for prediction capability, and fouling model parameters were regressed from the filtered data, after a specific mechanism was chosen. Several limitations were listed; neglecting shell side fouling is one of the most significant. The presence of faulty measurement instruments was also mentioned.

In order to establish a generally applicable methodology for calculating fouling model parameters from measured data, Costa et al. ${ }^{20}$ developed a computational routine for regressing fouling threshold models using a stochastic-deterministic hybrid optimization approach. The model predications were compared with real operational data from a Petrobras refinery in Brazil. The goodness-of-fit was evaluated by back-calculating the model parameters using several optimization methods such as Simplex and the Broyden-Fletcher-Goldfarb-Shanno algorithm (BFGS). The accuracy of the regression method was quantified by estimating the relative error between original and fitted parameters. The agreement was found to be acceptable, since the 
relative errors were not greater than $10 \%$ with respect to literature values for each fouling model parameter. In terms of optimality, by applying a hybrid optimization scheme, the presence of local optima was addressed. Overall, the proposed routine worked adequately, when only tubeside fouling was accounted for and no significant measurement errors were expected within the data.

In summary, significant advances have been achieved in the modeling of fouling deposition in crude oil refineries. These studies provide the research community more opportunities for closing the gap between empirical and first-principle approaches. The use of operational data has been gaining attention, but methods for increasing plant data reliability are still needed. This work develops a methodology for including the effect of measurement error in the estimation of fouling model parameters. Fouling deposition is accounted for separately for the shell-side and tube-side, represented by either threshold or simpler semi-empirical fouling models. Further complexity in the fouling modelling can be set in the form of different fouling models; but this paper focuses on combining a rigorous data reconciliation approach with parameter estimation. By implementing a gross error algorithm, this work aims and shows that is possible to identify faulty measurement instruments, as well as the conditions for compensating data miscalibrations.

The new approach for a single shell-and-tube heat exchanger undergoing fouling is described in Section 2, while Section 3 defines the data reconciliation and gross error detection methodology and highlights the importance of measurement error mitigation. Section 4 describes the parameter estimation scheme developed in this work. A description for the generation of operational synthetic data in this work is presented in Section 5. A case study, where the methodology is tested against simulated measured data, is shown in Section 6. The most important results are also analyzed and discussed. Finally, overall conclusions are presented in

\section{Section 7.}

\section{Heat exchanger modelling and simulation}

The heat exchanger model used in this work is applied to a single shell-and-tube multi-pass heat exchanger undergoing fouling deposition on the shell-side and tube-side. Shell-side fouling is expected in all heat transfer equipment, especially for crude oil applications where viscous fluids are used in most of heat exchangers within a pre-heat train ${ }^{13}$. To simplify the complexities associated with shell-side fouling modelling, this work uses a constant fouling rate model on the shell-side. Tube-side fouling is accounted for by applying existing fouling rate models, namely, 
the one proposed by Polley et al. ${ }^{17}$. This heat exchanger model can be applied to any commercially available equipment (e.g. straight, floating head, U-type tube bundle). Different geometric configurations are addressed by calculating both shell-side and tube-side local heat transfer coefficients, applying the correlations proposed by Wang et al ${ }^{15}$, which have been validated by comparison with globally accepted methods such as the Bell-Delaware method ${ }^{21}$.

This simulation is formulated under a pseudo-steady state. The time span is divided into a specific number of time-subintervals of the same length. Steady-state is assumed in each timeinterval, where the values of fouling resistances are updated from one time-interval to the next. The model applies the effectiveness and number of transfer units method $(\varepsilon-N T U)^{21}$ to calculate the operating conditions of the heat exchanger. Mass and energy balances assume no accumulation in each time-step and heat losses are assumed to be negligible. No changes in local conditions along each side of the heat exchanger are assumed, as lumped models for heat transfer are implemented to estimate the effect of fouling in the outlet conditions of the heat exchanger. Temperature-dependent physical properties can be implemented if either temperature-dependent correlations or plant data are available. Note that including temperature-dependence would require an iterative process to solve the system of equations. Initial conditions such as the inlet temperatures of streams, heat exchanger geometry and physical properties are needed to set up and solve the model.

Fouling deposition is considered as a dynamic process, the rate of which can be calculated using fouling rate models. At each time-step $\Delta t$, the heat exchanger fouling resistance is updated by means of an explicit Euler integration. It is assumed that the effect of deposit aging on any surface is negligible. This work allows for the presence of multiple fouling mechanisms on different sides of the heat exchanger. Consequently, a separated analysis regarding fouling resistance can take place (that is, fouling resistances for shell and tube side are calculated separately).

\subsection{Mass and energy balance}

For a single heat exchanger at steady state conditions, a mass balance for hot and cold streams is presented in Equations (1) and (2).

$m_{h, i}-m_{h, o}=0$
$m_{c, i}-m_{c, o}=0$ 
where the hot stream is denoted by the subscript $h$ and the cold stream is identified by the subscript $c$. Inlets and outlets to and from the heat exchanger are denoted by the subscripts $i$ and $o$ respectively; mass flow rate for each side of the heat exchanger is represented by $m$.

The energy balance is defined as the heat transferred from the hot stream to the cold stream. As steady-state is assumed, the heat absorbed by the cold stream has the same magnitude as that rejected by the hot stream. Mathematical expressions for each stream in the heat exchanger are given by Equations (3) to (5).

$\overline{C P}_{h}\left(T_{h, i}-T_{h, o}\right)=Q_{h}$

$\overline{C P}_{c}\left(T_{c, o}-T_{c, i}\right)=Q_{c}$

$Q_{h}=Q_{c}$

where $Q$ is the heat duty of on both sides of the heat exchanger and $\overline{C P}$ is the average heat capacity flow rate $(\overline{C P}=m \overline{c p}$, where $\overline{c p}$ is the average heat capacity for the temperature interval $\left.\left[T_{i}, T_{o}\right]\right)$. Temperatures for hot and cold streams are denoted by the variable $T$.

An extra, independent set of equations can be obtained by applying the concept of thermal effectiveness $(\varepsilon)^{21}$. According to this concept, thermal effectiveness is defined as the ratio between the actual amount of heat transferred in the heat exchanger, and the maximum heat transferred, defined by the maximum temperature difference that could be achieved in the heat exchanger (e.g. $\left.\left(T_{h, i}-T_{c, i}\right)\right)$. If the hot stream presents a lower value of heat capacity flow rate (hot stream is the minimum fluid) than that of the cold stream, the thermal effectiveness can be defined as in Equation (6).

$\varepsilon=\frac{\left(T_{h, i}-T_{h, o}\right)}{\left(T_{h, i}-T_{c, i}\right)}$

The heat capacity flow rate ratio $\left(C_{r}\right)$ is defined as the ratio between the minimum and maximum heat capacity flow rates. When the hot stream is the one with the lower heat capacity flow rate, Equation (5) can be re-arranged as it is shown in Equation (7). At the same time, Equation (6) can also be re-formulated as it is presented in Equation (8).

$T_{c, i}-T_{c, o}+C_{r} T_{h, i}-C_{r} T_{h, o}=0$

$\varepsilon T_{c, i}+(1-\varepsilon) T_{h, i}-T_{h, o}=0$

If the cold stream presents the lower heat capacity flow rate, the energy balance and effectiveness equations are described by Equations (9) and (10). 
$-C_{r} T_{c, i}+C_{r} T_{c, o}-T_{h, i}+T_{h, o}=0$

$(\varepsilon-1) T_{c, i}+T_{c, o}-\varepsilon T_{h, i}=0$

The entire set of equations from Equations (7) to (10) can be generalized into a single set of equations by introducing the binary variable $y_{c}$, where $y_{c}=1$ when the hot stream is the stream with the lower heat capacity flow rate. Otherwise, $y_{c}$ will be equal to zero ${ }^{22}$. The generalized formulation is shown in Equation (11).

$\left[\begin{array}{cccc}\varepsilon+\left(y_{c}-1\right) & -\left(y_{c}-1\right) & y_{c}-\varepsilon & -y_{c} \\ C_{r}\left(y_{c}-1\right)+y_{c} & -C_{r}\left(y_{c}-1\right)-y_{c} & C_{r} y_{c}+\left(y_{c}-1\right) & -C_{r} y_{c}-\left(y_{c}-1\right)\end{array}\right]\left[\begin{array}{c}T_{c, i} \\ T_{c, o} \\ T_{h, i} \\ T_{h, o}\end{array}\right]=0$

The simultaneous solution of Equation (11) gives the values for outlet temperatures when inlet conditions for the heat exchanger are provided. The solution can become iterative when temperature-dependent physical properties are considered. Note that an extra equation can be included by calculating the thermal effectiveness $\varepsilon$ as a function of the minimum heat capacity flow rate and number of transfer units $(N T U)$. The definition for a transfer unit is shown in Equation (12) ${ }^{21}$.

$N T U=\frac{U_{d} A}{(\overline{C P})_{\min }}$

where $U_{d}$ is the overall heat transfer coefficient for the heat exchanger, $A$ is the heat exchanger area and the subscript $\min$ stands for the minimum value of the heat capacity flow rate. If the number of transfer units, along with the heat exchanger flow arrangement, are known, the thermal effectiveness can be calculated using one of the relations shown in Equations (13) to (15), where Equation (13) is only valid for heat exchangers with one pass in the shell-side and two passes in the tube-side (also known as "1-2 shell-and-tube heat exchangers"), whereas Equations (14) and (15) are valid for heat exchangers with $n-2 n$ passes on shell-side and tube side respectively ${ }^{21}$. 


$$
\begin{aligned}
& \varepsilon=\frac{2}{\left(1+C_{r}\right)+\sqrt{C_{r}^{2}+1} \frac{1+\exp \left(-N T U \sqrt{C_{r}^{2}}+1\right)}{1-\exp \left(-N T U \sqrt{C_{r}^{2}}+1\right)}} \\
& \varepsilon=\frac{\left(1-\varepsilon_{a} C_{r}\right)^{n_{\text {shells }}}-\left(1-\varepsilon_{a}\right)^{n_{\text {shells }}}}{\left(1-\varepsilon_{a} C_{r}\right)^{n_{\text {shells }}}-C_{r}\left(1-\varepsilon_{a}\right)^{n_{\text {shells }}}} ; \text { for } C_{r} \neq 1 \\
& \varepsilon=\frac{n_{\text {shells }} \varepsilon_{a}}{1+\left(n_{\text {shells }}-1\right) \varepsilon_{a}} ; \text { for } C_{r}=1
\end{aligned}
$$

where $n_{\text {shells }}$ is the number of shell passes and the auxiliary variable $\varepsilon_{a}$ is calculated as in Equation (16).

$$
\varepsilon_{a}=\frac{2}{\left(1+C_{r}\right)+\sqrt{C_{r}^{2}+1} \frac{1+\exp \left(-N T U / n_{\text {shells }} \sqrt{C_{r}^{2}}+1\right)}{1-\exp \left(-N T U / n_{\text {shells }} \sqrt{C_{r}^{2}}+1\right)}}
$$

The calculation of the thermal effectiveness $\varepsilon$ is necessary to solve Equation (11) and to calculate the outlet temperatures of the heat exchanger, when only the inlet temperatures are known.

\subsection{Heat transfer and fouling modelling}

Fouling inevitably changes the thermal performance of a heat exchanger, as it adds-in an extra thermal resistance. These changes are reflected in the value of the overall heat transfer coefficient, where fouling deposition on either or both sides of the heat exchanger reduces the heat transfer performance by means of decreasing the heat load transferred between both streams.

This formulation integrates two different modelling strategies for heat transfer and fouling dynamics, as an innovative alternative to account independently for shell-side and tube-side fouling deposition.

\subsubsection{Overall and local heat transfer coefficients}

The individual fouling resistances from shell-side and tube-side are formulated in the overall heat transfer coefficient $U_{d}$ using Equation (17). An overall fouling resistance $R_{f}$ can be calculated by adding both contributions and adjusting the tube-side fouling resistance accordingly using the outer to inner diameter ratio $\left(d_{o} / d_{i}\right)$, as shown in Equation (18).

$U_{d}=\left[\left(\frac{1}{h_{\text {tube }}}+R_{f, \text { tube }}\right)\left(\frac{d_{o}}{d_{i}}\right)+\frac{1}{h_{\text {shell }}}+R_{f, \text { shell }}\right]^{-1}$ 
$R_{f}=R_{f, t u b e}\left(\frac{d_{o}}{d_{i}}\right)+R_{f, \text { shell }}$

where $h_{\text {tube }}$ and $h_{\text {shell }}$ are the average heat transfer coefficients for the shell-side and tube-side, respectively and $R_{f, \text { tube }}$ and $R_{f, \text { shell }}$ are the fouling resistances for both sides of the heat exchanger. Note that in Equation (17) the thermal resistance from the tube-wall is neglected.

Specific correlations for the shell-side and tube-side average heat transfer coefficient are implemented in this work. Special focus is given to the shell-side, where methods such as the Bell-Delaware ${ }^{21}$ do not perform as accurately as some commonly used commercial software, for example HTRI ${ }^{\circledR}$ and HEXTRAN ${ }^{\circledR 15}$. A simpler approach is used for the tube-side, where a set of correlations is applied, depending on the flow regime, indicated by the magnitude of tube-side Reynolds number $R e_{\text {tube }}$. These correlations are shown in Equations (19) to (22) ${ }^{15}$. For turbulent flow, an adjusted Dittus-Boelter ${ }^{23}$ correlation is used, depending if a cooling or heating process takes place in the heat exchanger.

$h_{\text {tube }}=\frac{\lambda_{\text {tube }}}{d_{i}} 1.86 \cdot\left(R e_{\text {tube }} \operatorname{Pr}_{\text {tube }} \frac{d_{i}}{L_{\text {tube }}}\right)^{\frac{1}{3}} ; R e_{\text {tube }} \leq 2100$

$h_{\text {tube }}=\frac{\lambda_{\text {tube }}}{d_{i}}\left(0.116 \cdot R e_{\text {tube }}^{\frac{2}{3}}-125\right) P r_{\text {tube }}^{\frac{1}{3}}\left[1+\left(\frac{d_{\text {in }}}{L_{\text {tube }}}\right)^{\frac{2}{3}}\right] ; 2100 \leq R e_{\text {tube }} \leq 10^{4}$

$h_{\text {tube }}=\frac{\lambda_{\text {tube }}}{d_{i}} 0.024 \cdot R e_{\text {tube }}^{0.8} \cdot P r_{\text {tube }}^{0.4} ; R e_{\text {tube }} \geq 10^{4}$ and heating

$h_{\text {tube }}=\frac{\lambda_{\text {tube }}}{d_{i}} 0.023 \cdot R e_{\text {tube }}^{0.8} \cdot P r_{\text {tube }}^{0.4} ; R e_{\text {tube }} \geq 10^{4}$ and cooling

where $P r_{\text {tube }}, L_{\text {tube }}$ and $\lambda_{\text {tube }}$ are the tube-side Prandtl number, single tube-length and thermal conductivity for the tube side fluid, respectively. Physical properties can be considered as constant through the tubes using a single value for each physical property, or by assuming a dependency between the property and the average temperature at both ends of the heat exchanger (for hot and cold streams). The tube-side flow velocity is calculated using available information about the tube geometry, number of tubes, number of tube-passes and tube-side flow rate.

The shell-side local heat transfer coefficient is calculated using a modified version of the correlation proposed by Ayub ${ }^{24}$. The modifications were developed by Wang et al. ${ }^{15}$, where physical properties such as shell-side fluid thermal conductivity $\left(\lambda_{\text {shell }}\right)$, heat capacity $\left(c p_{\text {shell }}\right)$ and viscosity $\left(\mu_{\text {shell }}\right)$ are used. Depending on the stream allocation in the heat exchanger, these physical properties can correspond to those for hot or cold streams. That is, if the hot stream is 
flowing though the shell-side, then $c p_{\text {shell }}=c p_{h}$. This work allocates the streams in such a way, since this preference is widely used in Western countries. The local heat transfer coefficient for the shell side is then defined by Equation (23) ${ }^{15}$.

$h_{\text {shell }}=\frac{0.06207 F_{S} F_{p} F_{L} \lambda_{\text {shell }}^{2 / 3}\left(c p_{\text {shell }} \mu_{\text {shell }}\right)^{1 / 3}}{d_{o}}$

where $F_{S}, F_{p}$ and $F_{L}$ are correction factors that account for different geometric and hydrodynamic features. The parameter $F_{S}$ accounts for the effects of baffle cut $\left(B_{C}\right)$, baffle arrangement and flow regime, according to the magnitude of shell side Reynolds number $\left(R e_{\text {shell }}\right)$. Equations (24) and (25) show different expressions for $F_{S}$ applied to different flow regimes.

$F_{s}=-5.9969 \cdot 10^{-4} R e_{\text {shell }}^{2}+0.6191 R e_{\text {shell }}+17.793 ; R e_{\text {shell }} \leq 250$

$F_{S}=1.40915 R e_{\text {shell }}^{0.6633} B_{C}^{-0.5053} ; 250 \leq R e_{\text {shell }} \leq 125000$

The correction factor $F_{p}$ is defined as the pitch factor, which changes with different tube pitch configurations. The parameter $F_{L}$ is known as the leakage factor. It mainly depends on the tube bundle configurations ${ }^{24}$.

\subsubsection{Fouling modelling}

To the authors' knowledge, fouling impacts both thermal and hydraulic performance in heat exchangers and a joint analysis including these two indicators is the most suitable approach. However, as a starting point, it is desired to test and validate the results of the proposed methodology in terms of the overall fouling resistance. For this reason, only thermal-related issues are addressed. Fouling dynamics are implemented within this heat exchanger simulation model by integrating a fouling rate model, over a discretized time span. An explicit Euler method is used, based on the work proposed by Rodriguez and Smith ${ }^{2}$. Thus, for two consecutive time intervals, the fouling resistance for a time step $n$ can be estimated using Equation (26).

$\left.R_{f}\right|_{n}=\left.R_{f}\right|_{n-1}+\left.\Delta t \frac{d R_{f}}{d t}\right|_{n-1}$

A fouling rate model needs to be chosen depending on the operating conditions and type of fluid flowing through each side of the heat exchanger. The selection of a fouling model should account for the deposition mechanism and it is crucial to choose each model accurately (for shell-side and tube-side). Previous studies have stated that for crude oil pre-heat trains, deposition of salt and waxes is likely at the cold end, whereas deposition by means of chemical reaction is encountered at the hot end ${ }^{5}$. In this work, given the complexity regarding shell-side 
fouling, a constant rate is used. Note that other types of fouling mechanisms (i.e. fouling models) could take place, but the effects of such mechanism in the shell-side geometry should be considered ${ }^{13}$. For the tube-side, the widely accepted chemical reaction model proposed by Polley et al. ${ }^{18}$, is chosen. Both fouling rate models are shown in Equations (27) and (28) respectively.

$\frac{d R_{f}}{d t}=\alpha_{1}$

$\frac{d R_{f}}{d t}=\alpha_{2} R e_{\text {tube }}^{-0.8} P r_{\text {tube }}^{-0.33} \exp \left(\frac{-E_{A}}{R_{g} T_{W}}\right)-\gamma R e_{\text {tube }}^{0.8}$

where $\alpha_{1}, \alpha_{2}$, the activation energy $E_{A}$ and $\gamma$ are the models' adjustable parameters, specific to the heat exchanger. $R_{g}$ is the ideal gas constant $\left(R_{g}=8.314 \cdot 10^{3} \mathrm{~kJ} \mathrm{~K}^{-1} \mathrm{~mol}^{-1}\right)$ and $T_{W}$ is the tubeside inlet wall temperature. This temperature is non-uniform along the tube-side, having a direct effect on the value of the fouling rate at the tube-side, as shown in Equation (28). A practical approach for calculating a representative fouling rate on the tube-side is to consider a linear increment in wall temperature, where values lie within the temperature range spanned by both ends of the tube-wall. This temperature range can be divided into several temperature-intervals of the same length ${ }^{2}$. Cold and hot end wall temperatures are defined by Equations (29) and (30).

$$
\begin{aligned}
& T_{W, c}=T_{c, i}+\frac{T_{h, o}-T_{c, i}}{h_{\text {tube }}\left[\left(\frac{1}{h_{\text {tube }}}+R_{f, \text { tube }}\right)\left(\frac{d_{o}}{d_{i}}\right)+\frac{1}{h_{\text {shell }}}+R_{f, \text { shell }}\right]} \\
& T_{W, h}=T_{c, o}+\frac{T_{h, i}-T_{c, o}}{h_{\text {tube }}\left[\left(\frac{1}{h_{\text {tube }}}+R_{f, \text { tube }}\right)\left(\frac{d_{o}}{d_{i}}\right)+\frac{1}{h_{\text {shell }}}+R_{f, \text { shell }}\right]}
\end{aligned}
$$

where $T_{W, c}$ and $T_{W, h}$ are the tube-wall temperatures at the cold and hot end of the tube-side, respectively. Values of the wall temperature are calculated along the tube-side; then a mean fouling rate can be determined by integrating each fouling rate for each temperature-interval. Equation (31) shows the formulation for calculating the value of the mean fouling rate ${ }^{2}$.

$\left.\frac{d R_{f, \text { tube }}}{d t}\right|_{\text {mean }}=\frac{\int_{T_{W, c}}^{T_{W, h}} \frac{d R_{f, \text { tube }}}{d t} d T_{W}}{T_{W, h}-T_{W, c}}$

The integral on the right hand side of Equation (31) is approximated using the trapezoidal rule over all the temperature intervals, for each time step ${ }^{2}$, although any integration technique could be used. 


\section{Data reconciliation and gross error detection}

In this work, a data reconciliation algorithm is applied to a single heat exchanger. It is assumed that flow rate and temperature measurements are available, and are obtained from specific measurement instruments, such as flow meters and thermocouples. Pressure measurements could be considered, provided that the heat transfer and fouling modeling include the hydraulic performance of such heat exchanger. The accuracy of each of these measurement instruments are assumed to be estimated as the standard deviation of each instrument. Random errors $\left(r_{\xi}\right)$ are assumed to be contained in each measurement and approximated as random variables, following a normal distribution with null mean and specific standard deviations for each measurement instrument ( $\sigma_{m}$ for flow rate and $\sigma_{T}$ for temperature measurements).

It is assumed that daily average data are used as process measurements and steady-state is considered for such set of data, as daily data are commonly used in industrial applications ${ }^{19}$. Based on these assumptions, the general data reconciliation problem can be formulated as described in Equation (32). The vector of reconciled data contains the estimated measurements that are as close as possible to the process measurements from each measurement instrument. Each measurement is weighted by its corresponding variance (square of each standard deviation) to account for the differences in accuracy among all measurement instruments. Note that this work assumes that all process variables (flow rates and temperatures) are measured. The effect of missing measurement can be included and it is planned to be considered in future contributions, by exploiting the available set of measurements and matrix-based techniques.

$$
\begin{gathered}
\min _{x_{R}}\left(x_{M}-x_{R}\right)^{T} \psi^{-1}\left(x_{M}-x_{R}\right) \\
\text { subject to } f\left(x_{R}\right)=0 \\
g\left(x_{R}\right) \leq 0 \\
x_{R}^{L} \leq x_{R} \leq x_{R}^{U}
\end{gathered}
$$

where $f$ and $g$ are equality and inequality constraints, $x_{M}$ and $x_{R}$ are the set of measured and reconciled values, $x_{R}^{L}$ and $x_{R}^{U}$ are lower and upper bounds for the optimization variables (reconciled values) respectively. The parameter $\psi$ is the covariance matrix, which is used for estimating the weights each measurement has in the objective function of Equation (32) ${ }^{25}$. The covariance matrix is assumed to be a diagonal matrix, in which each diagonal-element represents the variances of each flow rate and temperature measurement. Off-diagonal elements are taken to 
be zero, based on the assumption that there is no correlation among any set or subset of measurements, that is, all measurements are statistically independent from each other ${ }^{25}$. Statistical correlation among process measurements can be considered by estimating correlation indicators, which depend on the co-variance relating two or more different measurements. These values could then be located in their corresponding entries in the variance matrix $\psi$.

The solution of Equation (32) is expected to reach an optimal and non-biased result if and only if no gross errors are contained within the data ${ }^{11}$. The presence of gross errors can mislead reconciliation adjustments, directly affecting the level of expected reliability for the reconciled data ${ }^{11}$, that is, the degree at which the set of reconciled data satisfies each constraint and it is close to the set of process measurements. Hence, when gross errors are expected, their identification (detecting their presence) and estimation (calculating their numerical values) processes need to be considered along with any data reconciliation scheme.

\subsection{Nonlinear data reconciliation}

This work uses mass and energy balances as process constraints for solving the data reconciliation problem. Specifically, Equations (1) and (2), along with Equations (7) and (9) are used for this purpose. The reason for the selection of this set of equations is that they only involve values that can be either constant or measurement-dependent (e.g. heat capacity flow rate). The effect of fouling in the reconciliation approach is accounted for using temperature measurements, which at the same time define the values for the overall heat transfer coefficient $U_{d}$ and thermal effectiveness $\varepsilon$. Given the nonlinear nature of the above set of equations, the optimization problem defined in Equation (32) is solved using nonlinear programming techniques to achieve an optimum solution (i.e. minimize difference between process measurements and reconciled values) while solving the problem relatively fast.

The proposed methodology also applies lower and upper bounds for each measured value in the data reconciliation problem. An important feature of a nonlinear formulation is the fact that inequality constraints are accounted for, improving the feasibility of the final solution. In this work, a non-negativity constraint for the fouling resistance is set by considering the magnitudes of overall heat transfer coefficients for clean and fouled conditions. For each time step, if fouling is occurring in the heat exchanger, the value of $U_{d}$ is always less than the value of the clean 
(associated to a new or recently cleaned heat exchanger, i.e. at $t=0$ ) overall heat transfer coefficient $\left(U_{c}\right)$, defined in Equation (33).

$U_{c}=\left[\left(\frac{1}{h_{\text {tube }}}\right)\left(\frac{d_{o}}{d_{i}}\right)+\frac{1}{h_{\text {shell }}}\right]^{-1}$

This way, the inequality constraint can be defined as shown in Equation (34). Since the calculation of both overall heat transfer coefficients is based on process or simulated data, the fouling resistance obtained from this calculation can be regarded as a measured fouling resistance $\left(R_{f}^{m s r}\right)$. This constraint is used for ensuring that no fouling resistance exhibits a negative magnitude.

$R_{f}^{m s r}=\frac{1}{U_{d}}-\frac{1}{U_{c}} \geq 0$

Practically speaking, it is not possible to measure shell-side and tube-side fouling resistances directly, meaning that the definition for $U_{d}$ shown in Equation (17) cannot be used. To overcome this issue, the design equation for the heat exchanger is used, accounting for the heat duty $(Q)$, heat transfer area, logarithmic mean temperature difference $\left(\Delta T_{L M}\right)$, and the number of passes reflected in the correction factor $F_{t}$. This definition is formulated in Equation (35).

$U_{d}=\frac{Q_{h}}{A \Delta \mathrm{T}_{\mathrm{LM}} F_{t}}=\frac{Q_{c}}{A \Delta \mathrm{T}_{\mathrm{LM}} F_{t}}$

In this work, inequality constraints related to stream allocation (i.e. shell-side inlet temperature higher than tube-side inlet temperature) in the heat exchanger are not considered, as it is desired to maintain the problem formulation as flexible as possible. In other words, this methodology can be applied to shell-and-tube heat exchangers with different (and realistic) stream allocations.

This methodology solves the optimization problem stated in Equation (32) using the Sequential Quadratic Programming technique (SQP) ${ }^{26}$. This method presents certain advantages compared to other nonlinear solvers such as the Generalized Reduced Gradient method 26, when implementing data reconciliation. First, the objective function already has a quadratic form. Hence, only the set constraints need to be modified by linearization. Second, the Hessian matrix is constant, thus needs no updating, which speeds up each iteration when solving the data reconciliation problem ${ }^{25}$. The SQP method is chosen for the above reasons.

\subsection{Gross error detection and identification}

Systematic errors in the form of bias are considered in this work. That is, gross errors contained within a single or a set of measurements are addressed in this methodology. The effect 
of gross error is considered in the optimization problem of Equation (32) by adding its magnitude to the set of measured values, as shown in Equation (36) ${ }^{11}$.

$x_{M}=x_{R}+r_{\xi}+g_{\xi} B_{\xi}$

where $g_{\xi}$ is the magnitude of the gross error, which is a vector of single or multiple elements (gross error contained in one or multiple measurements). The matrix $B_{\xi}$ is a matrix whose elements are zero or one, depending on the relative position of the gross error with its corresponding measurement in the measurement vector. The product $g_{\xi} B_{\xi}$ results in the column vector containing the magnitudes of gross errors located in their corresponding measurements. Single or multiple biases are added into the set of optimization variables in such a way that the optimal solution includes the reconciled measurements along with the location and magnitudes of each gross error identified within the data.

When applying Equation (36) to find single or multiple gross errors, it is necessary to simultaneously estimate their location and magnitude. However, since gross errors may or may not exist within a set of measurements, before trying to estimate their values, the presence of such errors should be detected ${ }^{25}$.

In this work, the "global test" is used for addressing the detection problem ${ }^{27}$. This method uses a statistical test to determine the presence of gross errors. When using the global test, the vector of constraints residuals $\left(q_{\xi}\right)$, which depends on the value of the measured variables, and its covariance matrix $\left(\phi_{\xi}\right)$ are needed. For nonlinear systems, it is necessary to linearize the constraints, given that the global test has been developed only for linear systems ${ }^{25}$. After linearization, $q_{\xi}$ and $\phi_{\xi}$ can be calculated using Equations (37) and (38).

$q_{\xi}=J_{x_{M}} x_{M}-b_{x_{M}}$

$\phi_{\xi}=J_{x_{M}} \psi^{-1} J_{x_{M}}^{T}$

Where $J_{x_{M}}$ is the Jacobian matrix of the set of constraints evaluated at the measured variables, as shown in Equation (39). The value of $b_{x_{M}}$ in Equation (37) is determined by Equation (40).

$$
\begin{aligned}
& J_{x_{M}}=\left.\frac{d f\left(x_{R}\right)}{d x_{R}}\right|_{x_{M}} \\
& b_{x_{M}}=J_{x_{M}} x_{M}-f\left(x_{M}\right)
\end{aligned}
$$

The test function for the global test $(\tau)$ is defined in Equation (41). This function represents the mean value of the vector of residuals. When no gross errors are found, the function $\tau$ follows 
a $\chi^{2}$ probability distribution with $v$ degrees of freedom, at a specific level of significance $\delta^{11}$. Thus, null and alternative hypotheses are formulated, where the null hypothesis is set to be accepted when no gross errors are expected ${ }^{25}$. On the other hand, if a single or multiple gross errors are found, the alternative hypothesis is considered as valid.

$\tau=q_{\xi}^{T} \phi_{\xi}^{-1} q_{\xi}$

Typical values for $\delta$ are within the range of 5 to $10 \%$. The number of degrees of freedom is defined as the rank of matrix $J_{x_{M}}$, which accounts for the number of independent constraints. The value of $\tau$ is compared to a critical threshold value $\tau_{c}$, which depends on the available degrees of freedom and level of significance. If $\tau \leq \tau_{c}$, then gross errors are said to be detected. The value of $\tau_{c}$ is defined in Equation (42).

$\tau_{c}=\chi_{1-\delta}^{2}(v)$

Once the presence of a single or multiple gross errors is detected, their location and magnitudes are determined. A simultaneous solution for data reconciliation and gross error detection problem is developed in this work. The method is based on the algorithm proposed by Sánchez et al. ${ }^{28}$, where a set of conceivable bias candidates is determined by means of a recursive strategy in which each constraint is systematically analyzed for the presence of gross error. Next, a data reconciliation problem is solved for each combination of such candidates. A global test is also used as a stopping criterion, for selecting the combination of candidates for single or multiple gross errors. In the past, this approach has been applied to linear systems, where only mass balance equations are used as process constraints and an analytical solution is implemented for the reconciled values ${ }^{28}$.

As a modification to the previously mentioned strategy, SQP is used for solving the data reconciliation problem and at the same time, the locations and value of gross errors are determined. Different sets of gross errors presenting the same effect on the reconciliation problem (equivalent sets) and sets presenting linear dependency among each other (loops) are also considered, following the definitions proposed by Bagajewicz and Jiang ${ }^{29}$. For each set of gross error candidates, the data reconciliation problem is solved. The values of the objective function of Equation (32) are stored and calculated for each set of candidates. These magnitudes are compared among each other for identification of equivalences and loops within the data. If an equivalent set is found, the vector of reconciled values of each equivalent data-set are compared with additional information such as the design parameters (i.e. flow rates, temperatures). The set 
of reconciled values with the lowest absolute difference when compared to such additional information is selected and used at the next stages.

The performance of the gross error detection strategy (when simulating measurement error) is quantified via the overall power function $(O P F)^{25}$, defined in Equation (43). The overall power function indicates the number of gross errors perfectly identified, that is, if all gross errors in a specific set of measurements are found in their corresponding simulated measurements. The advantage of the overall power function is that it reflects the presence of mispredictions when detecting and identifying gross errors.

$O P F=\frac{\text { number of simulations with perfect identification }}{\text { number of simulations }}$

The maximum number of multiple gross errors that can be found is limited by the system's redundancy, that is, the number of variables that can be estimated using the process constraints, whether their measurements are available or removed ${ }^{25}$. If the interaction between streams and a heat exchanger is considered as an open system (i.e. no closed loops around the unit), then the maximum possible number of gross errors to be found simultaneously is equal to the number of process units in the system, when only mass balance constraints are considered ${ }^{29}$. In this work, only one process unit is assumed, a heat exchanger. Consequently, the gross error detection is limited to identify and estimate a single gross error in any process variable within the set of measurements. The data reconciliation and gross error detection method is summarized in Figure 1. Each step described in Figure 1 is applied to a set of data representing each time step. 


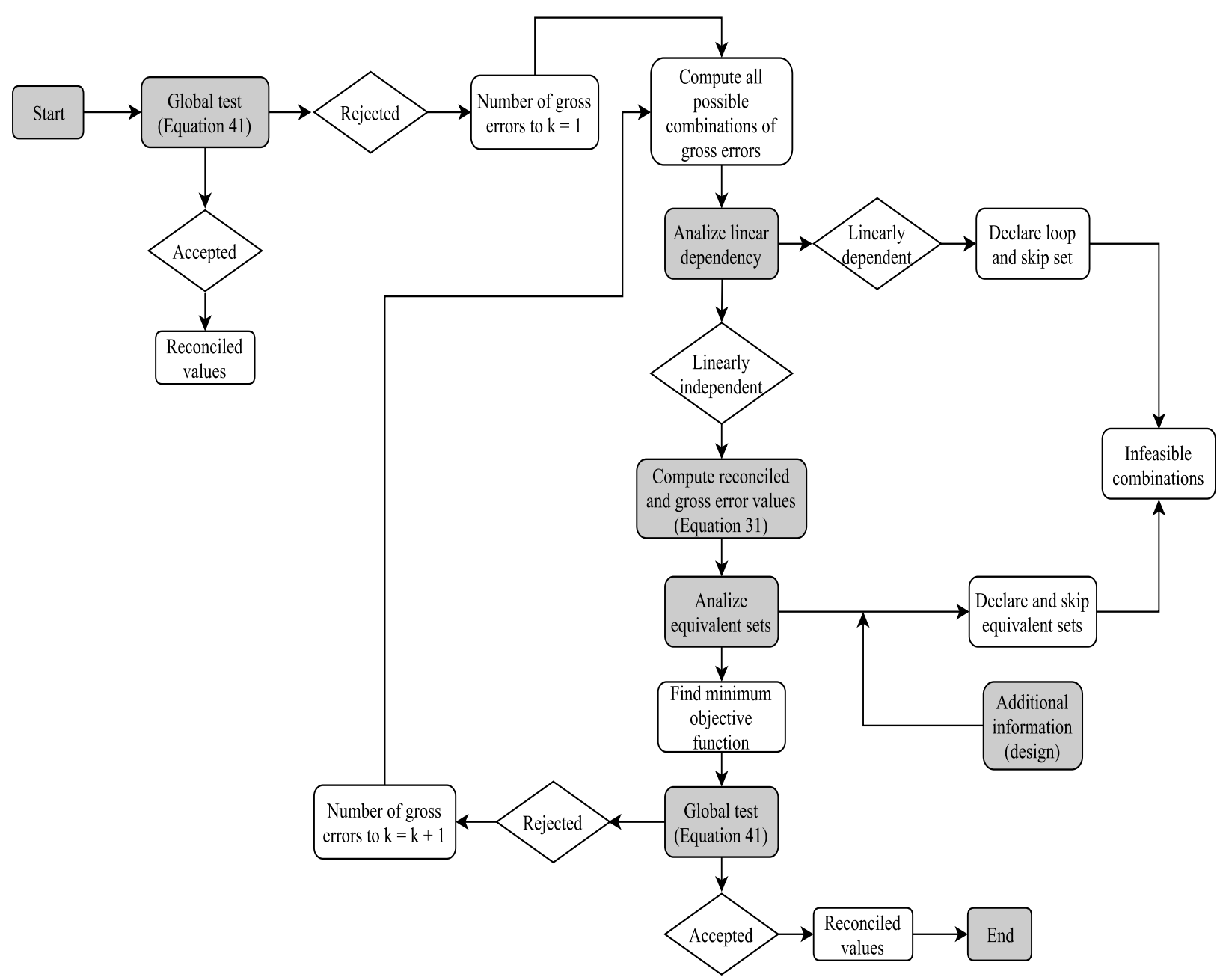

Figure 1: Gross error detection and identification schematic methodology

\section{Parameter estimation of fouling model parameters}

The next part of the methodology developed in this work is the calculation of fouling model parameters. These parameters are calculated by means of optimization, since each set of fouling model parameters is directly dependent on the type of crude oil. Several challenges are found when addressing the parameter estimation of fouling rate models, with three of them being the most significant ${ }^{20}$. First, there is a significant difference in magnitudes among each parameter for the same fouling rate model. These large differences impact the calculation of the optimal solution as the contribution of each optimization variable into the objective function becomes irregular, reflecting the differences in magnitude through the intermediate calculations of the solution algorithm. Secondly, the optimization problem presents multiple local optima, given by the nonlinear nature of some fouling rate models. Thirdly, these nonlinearities cause the solution of the optimization problem to have a high degree of dependency on the initial estimates.

As an example, Table 1 shows the values of the fouling rate model parameters determined by Polley et al. ${ }^{18}$. The specific units of these parameters have been compared with later research (Polley et al. ${ }^{17}$ ), as the reported values for the parameters present an inconsistency regarding the 
formation term in Equation (28). Given this issue, several simulations for a single heat exchanger were carried out, and the suitable units for each parameter were determined based on the results. The suitable units for each fouling parameter in Polley's model are reported in Table 1.

Table 1: Fouling model parameters (Equation (28)) determined by Polley et al. 18

\begin{tabular}{|c|c|c|}
\hline Parameter & Unit & Value \\
\hline$\alpha_{2}$ & $\mathrm{~m}^{2} \mathrm{~K} \mathrm{~kW}^{-1} \mathrm{~h}^{-1}$ & $1.00 \mathrm{e}+06$ \\
\hline$E_{A}$ & $\mathrm{~kJ} \mathrm{~mol}^{-1}$ & 48.0 \\
\hline$\gamma$ & $\mathrm{m}^{2} \mathrm{~K} \mathrm{~kW}^{-1} \mathrm{~h}^{-1}$ & $1.50 \mathrm{e}-09$ \\
\hline
\end{tabular}

Following the procedure proposed by Costa et al. ${ }^{20}$, to mitigate the effect of the large difference among fouling model parameters, a set of normalized optimization variables is defined as shown in Equations (44) - (47), where the symbol ( $)$ is used to denote normalized values, and the symbol $\left({ }^{\wedge}\right)$ denotes the parameters fitted via the parameter estimation algorithm.

$$
\begin{aligned}
& \tilde{\alpha}_{1}=\frac{\hat{\alpha}_{1}}{\alpha_{1}} \\
& \tilde{\alpha}_{2}=\frac{\hat{\alpha}_{2}}{\alpha_{2}} \\
& \tilde{E}_{A}=\frac{\hat{E}_{A}}{E_{A}} \\
& \tilde{\gamma}=\frac{\hat{\gamma}}{\gamma}
\end{aligned}
$$

The parameters in each denominator in Equations (44) - (47) is the set of base parameters for normalization, taken from specific fouling models found in the literature. For $\alpha_{1}$, its value is considered as a constant fouling rate model (see Equation (27)) and it is equal to $5.40 \mathrm{e}-05 \mathrm{~m}^{2} \mathrm{~K}$ $\mathrm{kW}^{-1} \mathrm{~h}^{-1}$. This value of fouling rate is considered to be relatively low and it has been used in a previous work ${ }^{2}$. The values corresponding with $\alpha_{2}, E_{A}$ and $\gamma$ are defined for chemical reaction fouling in Table 1and selected from the model developed by Polley et al. ${ }^{18}$, which has proven to predict fouling behavior with acceptable accuracy ${ }^{7}$.

Combining Equations (44) - (47) with the fouling models shown in Equations (27) - (28), the normalized fouling rate models are defined. This formulation is presented in Equations (48) and (49). 
$\frac{d R_{f}}{d t}=\alpha_{1} \tilde{\alpha}_{1}$

$\frac{d R_{f}}{d t}=\left(\alpha_{2} \tilde{\alpha}_{2}\right) R e_{\text {tube }}^{-0.8} \operatorname{Pr}_{\text {tube }}^{-0.33} \exp \left(\frac{-E_{A} \tilde{E}_{A}}{R_{g} T_{W}}\right)-(\gamma \tilde{\gamma}) R e_{\text {tube }}^{0.8}$

A two-level optimization scheme ${ }^{20}$ is used for addressing the problem of local optima. In this approach, a combination of stochastic search and deterministic solutions is used, in two different stages. In the first stage, a Genetic Algorithm (GA) ${ }^{30}$ is implemented. The solution is found by randomly generating a series of set of individuals (population). Every time a new iteration (or generation) is to be produced, the next population is created by analyzing the value of the objective function (fitness value) for each set of individuals. This analysis is carried out by applying specific operators to each generation, consisting of crossover, selection and mutation. Since each population is generated by applying random moves (after selecting the most suitable individuals for minimization), the algorithm allows for a wide search, minimizing the likelihood of getting trapped in local optima. Consequently, no initial estimations are needed, which addresses the third and last challenge discussed previously. Note that the use of Genetic Algorithm is not strict for this problem, as alternative methods that are independent from initial guesses could also bring successful results. In the second stage, the solution from the stochastic optimization is fine-tuned by using this solution as an initial estimate for a deterministic solver. The degree of fine-tuning was tested by studying the change (relative to the stochastic solution) in each fitted parameter once the deterministic optimization was applied. The Interior Point method ${ }^{26}$ was selected, as it was able to re-adjust the set of parameters when using the solution from the stochastic optimization. Subsequently, a feasible solution that satisfies the set of constraints is obtained and used for further assessment and predictions on the heat exchanger. The performance of this strategy has been tested and validated ${ }^{20}$. Hence, this hybrid approach is selected as it provides a widespread search for a solution, without depending on initial estimates, in contrast with alternative methods such as global optimization techniques.

For the objective function, it is desired to minimize the root mean square error (RMSE) between the fouling resistances calculated from the reconciled data $\left(R_{f}^{m s r}\right)$ using Equation (34), and from the ones calculated using the fouling rate models for shell-side and tube-side $\hat{R}_{f}$ (Equations (27) and (28)). The values of the fitted fouling resistances can be obtained using the fitted parameters and the definitions shown in Equations (26) to (28), for each time step. The 
objective function is defined in Equation (50), where each time step is represented by $n$, and the total number of time steps by $k$.

$$
\begin{gathered}
\min _{\widetilde{\alpha}_{1}, \widetilde{\alpha}_{2}, \tilde{E}_{A}, \widetilde{\gamma}} \sqrt{\frac{\sum_{n=1}^{k}\left(R_{f, n}^{m s r}-\hat{R}_{f, n}\right)^{2}}{k}} \\
\text { subject to } \\
\tilde{\alpha}_{1}^{L} \leq \tilde{\alpha}_{1} \leq \tilde{\alpha}_{1}^{U} \\
\tilde{\alpha}_{2}^{L} \leq \tilde{\alpha}_{2} \leq \tilde{\alpha}_{2}^{U} \\
\tilde{E}_{A}^{L} \leq \tilde{E}_{A} \leq \tilde{E}_{A}^{U} \\
\tilde{\gamma}^{L} \leq \tilde{\gamma} \leq \tilde{\gamma}^{U}
\end{gathered}
$$

The upper and lower bounds are set for the measured fouling resistances by fixing limiting values for each fouling model parameter, based on their normalized form. In order to have a robust solution, these bounds are defined within a wide range of values.

\section{Synthetic data generation}

Operational data are to be used for the application of this methodology. For careful control of the testing, synthetic data were generated. The simulation strategy presented in Section 2 is implemented to replicate industrial measurements. To include the effect of measurement error, random and gross errors are added into the data.

Random error is included by adding a random value to its corresponding simulated measurement. The magnitude of each random error is generated using the built-in function normrnd in MATLAB. Following the definitions stated by Narasimhan and Jordache ${ }^{25}$, these random values are generated by setting a normal Gaussian distribution with a mean value of zero and standard deviation of $1.5 \mathrm{~kg} \mathrm{~s}^{-1}$ and $1.0^{\circ} \mathrm{C}$ for flow rates and temperatures, respectively ${ }^{31,32}$. Note that in the case of flow meters, percentages of $1.0 \%$ of the value of the measurement are commonly used and a fixed upper bound of $1.5 \mathrm{~kg} \mathrm{~s}^{-1}$ is selected in this work for the sake of robustness regarding the different orders of magnitude for shell-side and tube-side flow rates. These values are within acceptable ranges in commonly used instruments such as thermocouples and ultrasonic flow meters. Gross error is included by adding a constant value (over time) to any individual or set of measurements. Gross errors can change their magnitude over time, but these changes are not significantly different between consecutives time steps ${ }^{25}$. Usually, gross errors present higher magnitudes to any random error and they are produced by malfunctions or 
miscalibrations of any measurement instrument. Any detection and identification of gross error is applied using a level of significance $\delta$ of 0.1, i.e. a confidence level of $90 \%$ (see Equation (42)).

\section{Case study}

The methodology described in Sections 2 to 4 is applied for simulating and assessing fouling development and data reliability on a multi-pass shell-and-tube heat exchanger. Figure 2 illustrates the heat exchanger used in this case study. The selected heat exchanger is a modification from the last exchanger of the pre-heat train studied by Ahmad et al. ${ }^{33}$. Physical properties ${ }^{33}$ for each fluid in the heat exchanger are provided in Table 2. Crude oil is flowing through the tube-side, while atmospheric residue is the hot stream in the shell-side. Note that the temperature-dependency in physical properties plays an important role in the simulation and optimization strategies (data reconciliation and parameter estimation). The more complex are the relations among process variables and physical properties, the greater the effect of these relations on the parameter estimation results. This effect is also reflected in computational time, as a greater number of calculations are needed for solving the parameter estimation problem.

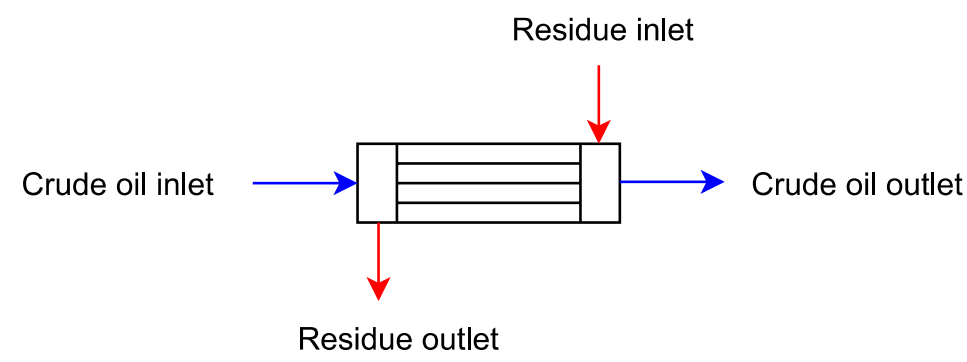

Figure 2: Crude oil heat exchanger used for case study

The analysis of three different cases (see Table 3.) is presented for assessing the effect of the measurement error in the solution of the parametric fitting. In other words, it is desired to understand the relevance of the presence and magnitudes of measurement error. Geometric parameters and inlet operating conditions are shown in Table 4. In this case study, temperaturedependence for each physical property is ignored.

Table 2: Physical properties for each stream of case study

\begin{tabular}{|c|c|c|c|}
\hline Parameter & Units & Crude oil & Residue \\
\hline Density & $\mathrm{kg} \mathrm{m}^{-3}$ & 748.60 & 830.00 \\
\hline Thermal conductivity & $\mathrm{W} \mathrm{m}^{-1} \mathrm{~K}^{-1}$ & $9.60 \mathrm{e}-02$ & $8.50 \mathrm{e}-02$ \\
\hline Viscosity & $\mathrm{Pa} \mathrm{s}^{-1}$ & $0.60 \mathrm{e}-03$ & $2.00 \mathrm{e}-03$ \\
\hline Specific heat & $\mathrm{J} \mathrm{kg}^{-1} \mathrm{~K}^{-1}$ & $2.82 \mathrm{e}+03$ & $2.82 \mathrm{e}+03$ \\
\hline
\end{tabular}


The simulation time is one year, and it is assumed that each process variable (flow rate and temperature) in the heat exchanger is measured. Steady-state is assumed and daily-averaged sets of synthetic measurements are used as operational data. The entire set of measurements is divided into two subgroups, with the purpose of determining a reliable and accurate degree of prediction.

Table 3: Description of analyzed cases

\begin{tabular}{|c|c|}
\hline Case number & Description \\
\hline 1 & No measurement error in data \\
\hline 2 & Only random errors, no data reconciliation \\
\hline 3 & Only random errors, with data reconciliation \\
\hline 4 & Random and gross errors considered \\
\hline
\end{tabular}

An "estimation set" of data is defined as the first $50 \%$ of data obtained from the data reconciliation procedure. These data are used as an input for the parametric fitting. The second set of data is used for comparison after calculating the fouling resistances for the same time period, using the fitted models determined by using the estimation set. This approach is chosen for using the fitted parameters with a different set of data, and tests the predictive capabilities of the fouling rate models. A simulation of the heat exchanger using the fitted models is used to analyze the prediction capabilities of the fitted model. Outlet temperatures are selected as a criterion for this comparison. Shell-side and tube-side fouling are represented by the fouling rate models from Equations (27) and (28).

Table 4: Geometric and stream data for case study

\begin{tabular}{|c|c|c|}
\hline Parameter & Units & Value \\
\hline Tube pitch & $\mathrm{m}$ & $2.54 \mathrm{e}-02$ \\
\hline Number of tubes & -- & 250 \\
\hline Number of tube passes & -- & 1.00 \\
\hline Tube length & $\mathrm{m}$ & 7.50 \\
\hline Tube layout angle & $\circ$ & 30.0 \\
\hline Tube inner diameter & $\mathrm{m}$ & $1.54 \mathrm{e}-02$ \\
\hline Tube outer diameter & $\mathrm{m}$ & $1.90 \mathrm{e}-2$ \\
\hline Shell inner diameter & $\mathrm{m}$ & 0.75 \\
\hline Number of shell passes & -- & 1.00 \\
\hline Number of baffles & -- & 25.0 \\
\hline Baffle spacing & $\mathrm{m}$ & $3.00 \mathrm{e}-01$ \\
\hline Inlet baffle spacing & $\mathrm{m}$ & $1.50 \mathrm{e}-01$ \\
\hline Outlet baffle spacing & $\mathrm{m}$ & $1.50 \mathrm{e}-01$ \\
\hline Baffle cut & $\%$ & 20.0 \\
\hline Tube bundle clearance & $\mathrm{m}$ & $6.00 \mathrm{e}-02$ \\
\hline Crude oil flow rate & $\mathrm{kg} \mathrm{s}^{-1}$ & 77.7 \\
\hline Crude oil inlet temperature & ${ }^{\circ} \mathrm{C}$ & 210.0 \\
\hline Residuum flow rate & $\mathrm{kg} \mathrm{s}^{-1}$ & 34.54 \\
\hline Residuum inlet temperature & ${ }^{\circ} \mathrm{C}$ & 334 \\
\hline
\end{tabular}


The heat exchanger simulation, data reconciliation and parameter estimation methods are coded in MATLAB, where the input information is integrated to the main algorithm by using Microsoft Excel spreadsheets for the heat exchanger geometry and stream specifications. These calculations are done by a computer with an Intel Core i5 processor of $3.20 \mathrm{GHz}$ and $8.00 \mathrm{~GB}$ of installed RAM. In order to account for the effect of different levels of complexity (i.e., cases 1 to 4), each case from Table 3 is analyzed separately. For all cases, a single set of optimization parameters is used. This set of parameters for all cases is shown in Table 5. The in-built Genetic algorithm solver $g a$ in MATLAB is used, which uses decimal encoding and an intermediate crossover function that takes a weighted average of the parents for generating a child for the next generation. The mutation function is shown in Table 5, which is selected as such function adapts the mutation actions accordingly depending on the changes between generations and the inequality constraints. In order to prioritize mutation actions for next generations, the stochastic nature of the solver is exploited by choosing a low value of crossover fraction. The number of generations and size of the population matrix are based on the number of optimization variables.

Table 5: Optimization parameters for estimation of fouling models

\begin{tabular}{|c|c|}
\hline Parameter & Value \\
\hline Population size & 400 \\
\hline Maximum number of generations & 400 \\
\hline Crossover fraction & 0.20 \\
\hline Number of optimization variables & 4.00 \\
\hline Mutation function & 'Adaptive Feasible' \\
\hline
\end{tabular}

Lower and upper bounds for the optimization variables are applied for all cases. For each parameter, a wide range of values is selected, as it is desired to maintain a flexible and robust set of parameters, which can capture the uniqueness of a specific type of crude oil when necessary. The values for these lower and upper bounds are reported in Table 6. Normalized bounds (dimensionless) are set for these cases, since the optimization problem is solved based on the normalization procedure described in Section 4. A narrower range of bounds is selected for the activation energy, where typical values for Polley's model on crude oil applications are found within the range of 38 and $59 \mathrm{~kJ} \mathrm{~mol}^{-1} 16$.

Table 6: Lower and upper bounds for parameter estimation

\begin{tabular}{|c|c|c|}
\hline Normalized parameter & Lower bound & Upper bound \\
\hline$\tilde{\alpha}_{1}$ & 0.00 & 10.0 \\
\hline$\tilde{\alpha}_{2}$ & 0.00 & 10.0 \\
\hline$\tilde{E}_{A}$ & 0.50 & 2.0 \\
\hline$\tilde{\gamma}$ & 0.00 & 10.0 \\
\hline
\end{tabular}




\subsection{Case 1: No measurement error within data}

The parameter estimation approach is tested by neglecting the effect of measurement error and back-calculating each fouling model parameter from the simulated data. These results are compared with the base-values. No data reconciliation is implemented in this case, as no measurement error is considered. The results from the parameter estimation are shown in Table 7. The results show significant differences between the two sets; these can be explained by the fact that different approaches are used for calculating both sets of fouling resistances; in the case of measured fouling resistances, Equation (34) is used, where only an overall value of this variable is considered, without any regard to the contribution from each side of the heat exchanger. On the other hand, the effect of shell-side and tube-side fouling deposition is accounted for when solving the parameter estimation problem, where Equation (26) is used for shell-side and tube-side separately.

Good agreement is obtained, as shown in Figure 3 and Figure 4, where predictions for fouling resistance and outlet temperatures for the heat exchanger are depicted and reflected in the value of the RMSE in Table 7. The plots show an accurate fit for both variables, which is expected given the fact that measurement error is not considered in this case.

Table 7: Fitted fouling rate model parameters for Case 1

\begin{tabular}{|c|c|c|}
\hline Parameter & Units & Value \\
\hline$\hat{\alpha}_{1}$ & $\mathrm{~m}^{2} \mathrm{~K} \mathrm{~kW}^{-1} \mathrm{~h}^{-1}$ & $2.23 \mathrm{e}-04$ \\
\hline$\hat{\alpha}_{2}$ & $\mathrm{~m}^{2} \mathrm{~K} \mathrm{~kW}^{-1} \mathrm{~h}^{-1}$ & $4.65 \mathrm{e}+06$ \\
\hline$\hat{E}_{A}$ & $\mathrm{~kJ} \mathrm{~mol}^{-1}$ & 55.04 \\
\hline$\hat{\gamma}$ & $\mathrm{m}^{2} \mathrm{~K} \mathrm{~kW}^{-1} \mathrm{~h}^{-1}$ & $7.57 \mathrm{e}-09$ \\
\hline RMSE & -- & $5.17 \mathrm{e}-04$ \\
\hline
\end{tabular}

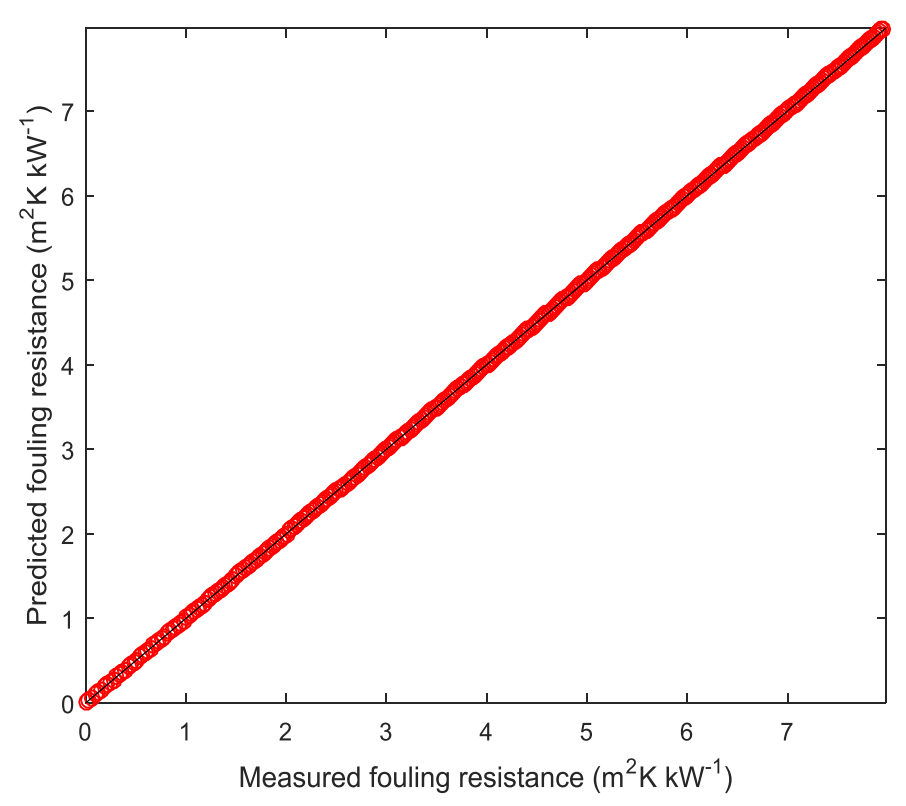

Figure 3: Parity plot for fouling resistance $R_{f}$ : Case 1 


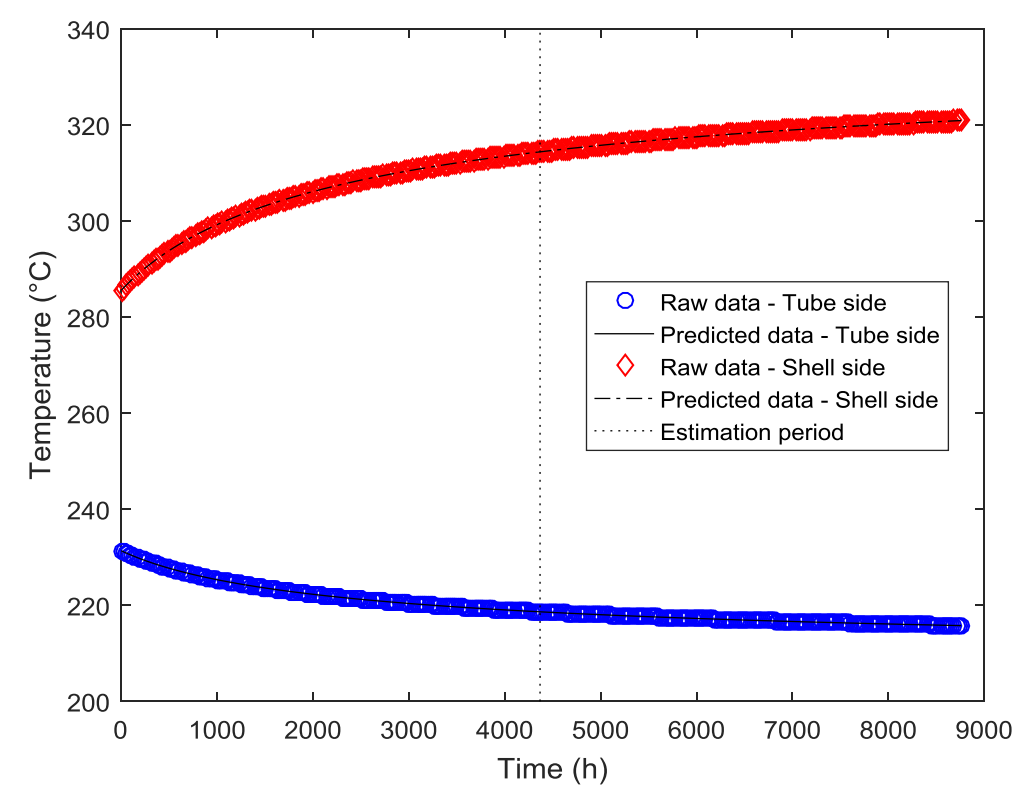

Figure 4: Simulated (synthetic data) and predicted (fitted model) outlet temperatures for tubeside and shell-side: Case 1

\subsection{Case 2: Parametric fitting without data reconciliation and considering only random errors}

As described in Section 5, random errors are added to the data-points using known values for standard deviations, and generated for each time step. That is, for the same process variable, different values of random error are added at each time step. The parameter estimation strategy is applied using the raw data, without considering data reconciliation. The flow rate and temperature simulated measurements are illustrated in Figure 5.

The results of the parametric fitting are shown in Table 8 . The estimated parameters present (as in Case 1) significant differences between the two sets of parameters. The value of the RMSE is higher than that of Case 1. This increase is (as expected) directly related to the presence of random errors in the flow rate and temperature measurements, which is further propagated to the calculation of fouling resistance.

Table 8: Fitted fouling rate model parameters for Case 2

\begin{tabular}{|c|c|c|}
\hline Parameter & Units & Value \\
\hline$\hat{\alpha}_{1}$ & $\mathrm{~m}^{2} \mathrm{~K} \mathrm{~kW}^{-1} \mathrm{~h}^{-1}$ & $3.50 \mathrm{e}-07$ \\
\hline$\hat{\alpha}_{2}$ & $\mathrm{~m}^{2} \mathrm{~K} \mathrm{~kW}^{-1} \mathrm{~h}^{-1}$ & $4.32 \mathrm{e}+05$ \\
\hline$\hat{E}_{A}$ & $\mathrm{~kJ} \mathrm{~mol}^{-1}$ & 43.91 \\
\hline$\hat{\gamma}$ & $\mathrm{m}^{2} \mathrm{~K} \mathrm{~kW}^{-1} \mathrm{~h}^{-1}$ & $1.49 \mathrm{e}-08$ \\
\hline RMSE & -- & 0.103 \\
\hline
\end{tabular}




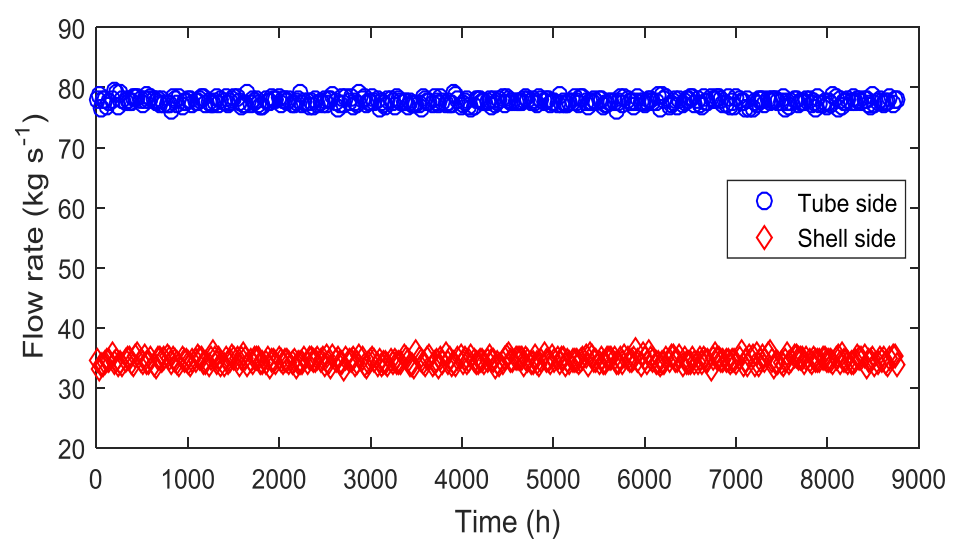

(a)

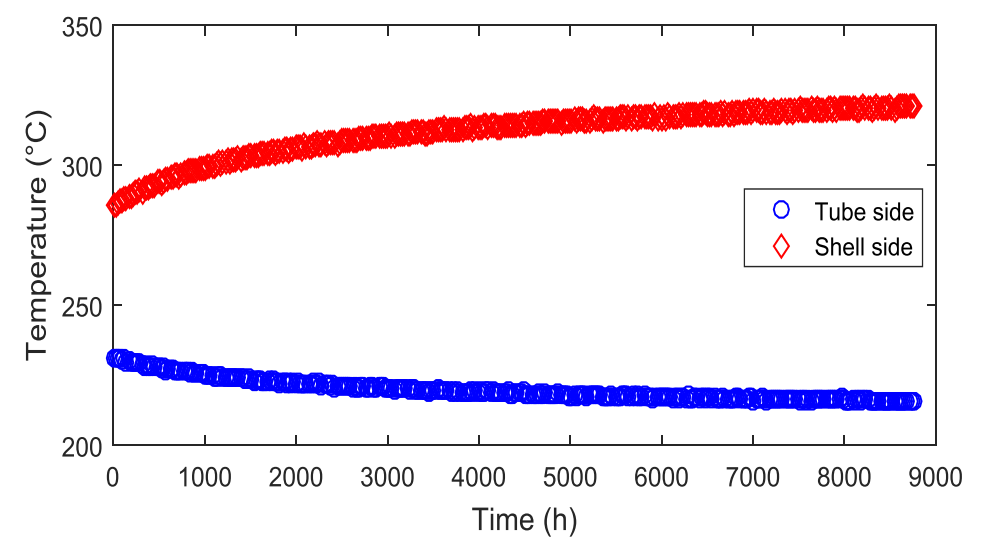

(b)

Figure 5: Simulated (synthetic) flow rates and outlet temperatures for (a) tube-side and (b) shellside: Case 2

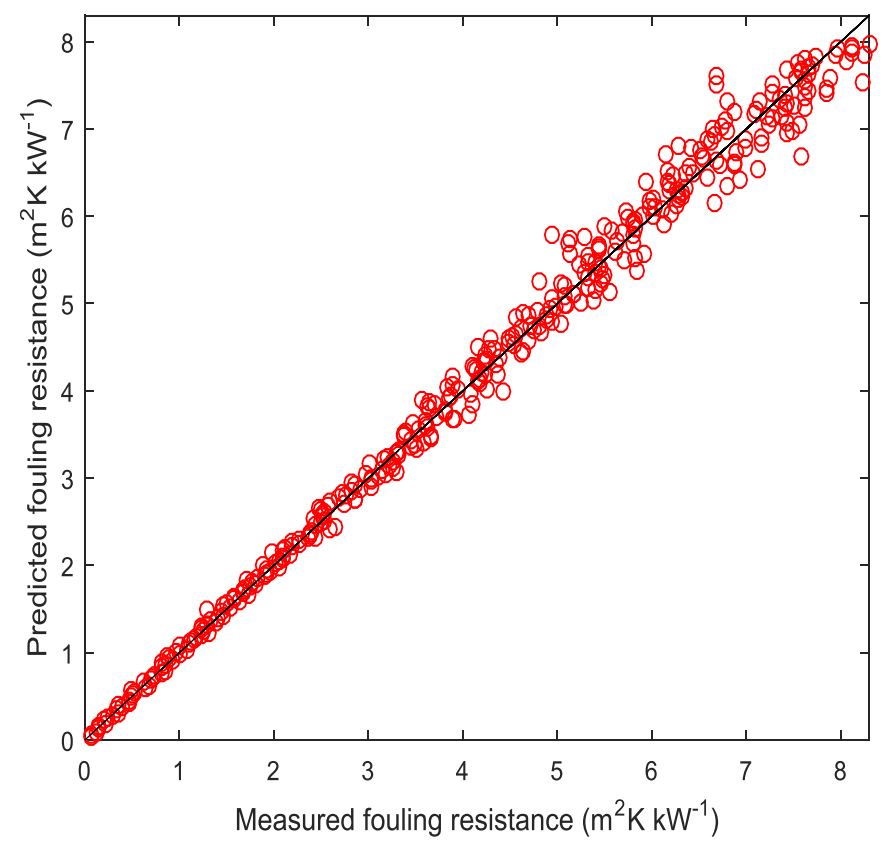

Figure 6: Parity plot for fouling resistance $R_{f}$ : Case 2

A comparison of predicted and measured fouling resistance is shown in Figure 6. As it can be seen, each point corresponding to the fouling resistance evolution through time is more scatter compared to Case 1 . In the next case, these results are contrasted with a parameter estimation considering the reconciliation of measurements. 
The effect of random error and data reconciliation in the parameter estimation for fouling rate models are now studied.

The results from the data reconciliation are shown in Figure 7. The results show that the reconciliation performance in the flow rate for shell-side and tube-side is significantly reduced, as shown in Figure 7(a). On the other hand, from Figure 7(b), it can be seen that this is not the case for the temperature measurements. Nevertheless, both mass and energy balances are satisfied and the adjustments alleviate the impact of random noise for this set of measurements. The main difference between the results for the reconciliation of flow rates and temperatures is the use of flow rate specifications for both sides of the heat exchanger. The flow rates for inlet and outlet conditions are related through mass balance equations. This fact reflects in the data reconciliation results, as the flow rate information is used as a direct constraint, whereas for outlet temperatures nonlinear relations are used for calculating and estimating the reconciled values. This increase in nonlinear complexity has a direct impact on the reconciliation solution. As a consequence, the overall reconciliation performance is relatively adequate, but sufficient so the energy process constraints are satisfied for all measurements.

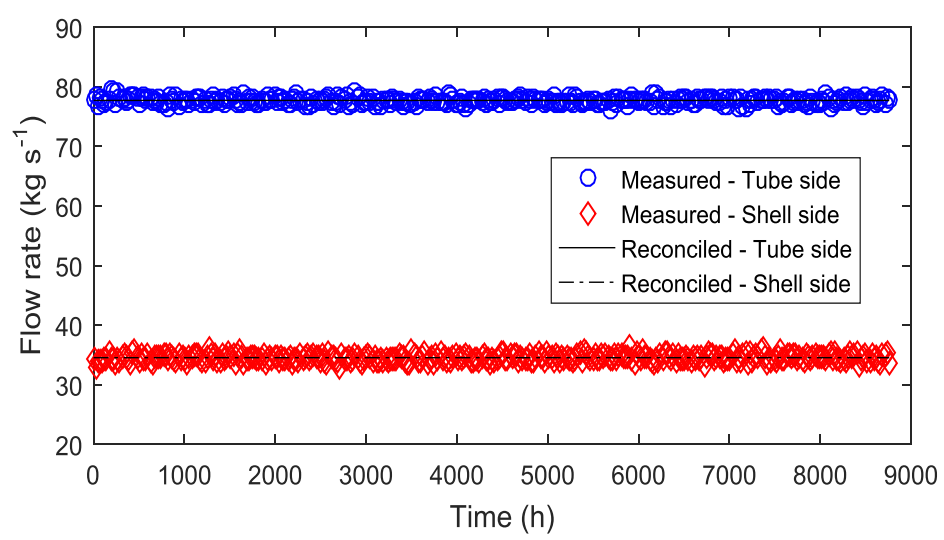

(a)

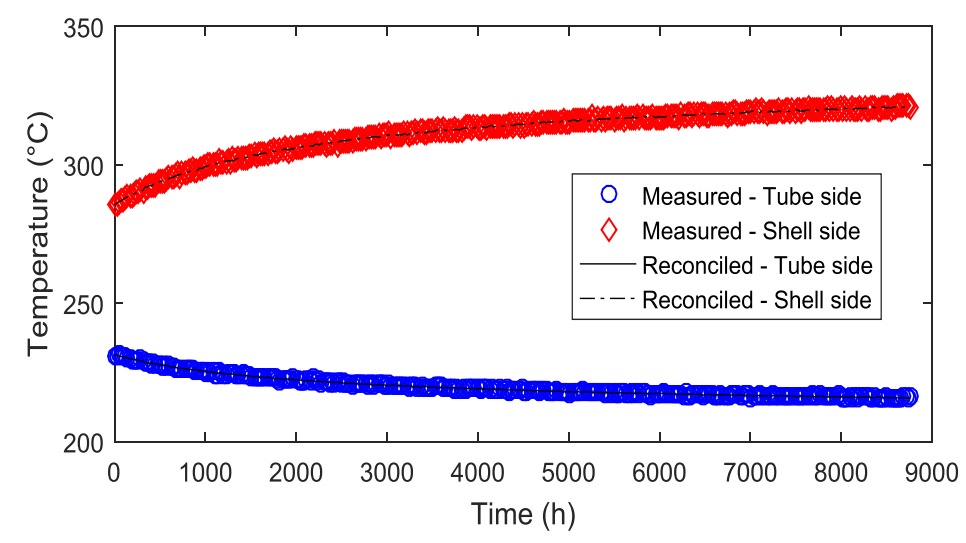

(b)

Figure 7: Data reconciliation results for (a) flow rates and (b) outlet temperatures for tube-side and shell-side: Case 3 
The performance of the data reconciliation can be quantified by analyzing the reduction in standard deviation for all measurements, across the entire time span. If the data reconciliation is able to reduce the magnitude of random errors completely, the standard deviation for the reconciled measurement error will be close to zero, as a negligible magnitude of measurement error is contained within the data-set. The standard deviations of the measurement error for flow rates and temperatures before and after data reconciliation were calculated. An annual average for the standard deviation is obtained, and these values are used to calculate the reduction of standard deviation before and after reconciliation. The mean values of standard deviation before and after data reconciliation and the relative percentage of reduction of standard deviation $\left(\operatorname{err}_{s d}\right)$ (defined in Equation (51)), are shown in Table 9, for flow rate and temperature measurements.

$e r r_{s d}=\left(\frac{\sigma^{\text {before }}-\sigma^{\text {after }}}{\sigma^{\text {before }}}\right) \cdot 100$

where $\sigma^{\text {before }}$ and $\sigma^{\text {after }}$ are the standard deviations of the data-set (flow rates or temperatures) before and after data reconciliation.

Table 9: Standard deviation and percentage of reduction of standard deviation for measurement errors in flow rates and temperatures

\begin{tabular}{|c|c|c|c|}
\cline { 2 - 4 } \multicolumn{1}{c|}{} & $\boldsymbol{\sigma}^{\text {before }}$ & $\boldsymbol{\sigma}^{\text {after }}$ & Reduction in standard deviation (\%) \\
\hline Flow rates & 0.29 & $2.0 \mathrm{e}-12$ & 100 \\
\hline Temperatures & 0.19 & 0.07 & 62.0 \\
\hline
\end{tabular}

The results from Table 9 show that the data reconciliation is better for flow rate measurements than for the corresponding temperatures. These results are consistent with the points made about the effect of nonlinearities on each energy constraint. These figures also validate the idea that each process constraint is suitably satisfied, as the values of standard deviations of the measurement errors are greatly reduced after reconciliation.

The fouling model parameters are fitted using the set of reconciled data. The results are presented in Table 10, with their corresponding RMSE. The set of parameters differs from that shown in Table 7. The main reason for these differences is the presence of random error, which has been partially reduced after reconciling each measurement. The values of the fouling parameters are within expected ranges, where the parameter $\gamma$ presents a value close to its upper bound (i.e. $1.50 \mathrm{e}-08 \mathrm{~m}^{2} \mathrm{~K} \mathrm{~kW}^{-1} \mathrm{~h}^{-1}$ ). Note that these results show that a different set of fouling model parameters can be fit to regress and predict the same fouling resistance and thermal 
performance. The capability of identifying the correct fouling mechanism in both sides of the heat exchanger is limited to either previous or fundamental information regarding the fouling phenomenon in the shell-side and the tube-side. The fouling model parameters are used to predict the outlet temperatures and fouling resistance of the heat exchanger, just as in Case 1 and 2. A parity plot for fouling resistance is depicted in Figure 8. As the value of the fouling resistance increases, several predicted points tend to have a higher difference compared to that of the set of reconciled values. Nevertheless, the overall performance in terms of predictions of outlet temperatures is satisfactory. Figure 9 illustrates the agreement between reconciled and predicted data for both stream temperatures, which also validates the satisfaction of mass and energy constraints set in the data reconciliation problem. Moreover, the value of the RMSE is lower than that of Case 2. This difference evidences the relevance of the data reconciliation for improving the accuracy of the parameter estimation strategy for assessment and prediction of the fouling behavior.

It is possible to quantify the agreement for temperature predictions by analyzing the absolute error between predicted and reconciled values. The absolute error $\left(a b s_{T}\right)$ for outlet temperatures in both sides of the heat exchanger is defined in Equation (52), where $T_{o}^{m s r}$ and $\hat{T}_{o}$ are the measured (synthetic) and fitted outlet temperatures for shell-side and tube-side of the heat exchanger, respectively. Figure 10 shows histograms for shell-side and tube-side outlet temperatures. The absolute errors values are within the ranges of as -0.23 and $0.23^{\circ} \mathrm{C}$ for the tube-side, and -0.52 and $0.52^{\circ} \mathrm{C}$ for the shell-side respectively. These differences are considered acceptable, since both of these values have a low frequency, meaning that they do not repeat themselves within the data-set as much as the rest. It may be concluded that the data reconciliation approach reduces the effect of random error from the set of measurements, and allows for reliable parameter estimation and prediction of outlet thermal conditions.

$a b s_{T}=T_{o}^{m s r}-\widehat{T}_{o}$

Table 10: Fitted fouling rate model parameters for Case 3

\begin{tabular}{|c|c|c|}
\hline Parameter & Units & Value \\
\hline$\hat{\alpha}_{1}$ & $\mathrm{~m}^{2} \mathrm{~K} \mathrm{~kW}^{-1} \mathrm{~h}^{-1}$ & $9.16 \mathrm{e}-07$ \\
\hline$\hat{\alpha}_{2}$ & $\mathrm{~m}^{2} \mathrm{~K} \mathrm{~kW}^{-1} \mathrm{~h}^{-1}$ & $5.03 \mathrm{e}+05$ \\
\hline$\hat{E}_{A}$ & $\mathrm{~kJ} \mathrm{~mol}^{-1}$ & 44.58 \\
\hline$\hat{\gamma}$ & $\mathrm{m}^{2} \mathrm{~K} \mathrm{~kW}^{-1} \mathrm{~h}^{-1}$ & $1.48 \mathrm{e}-08$ \\
\hline RMSE & -- & $4.43 \mathrm{e}-02$ \\
\hline
\end{tabular}




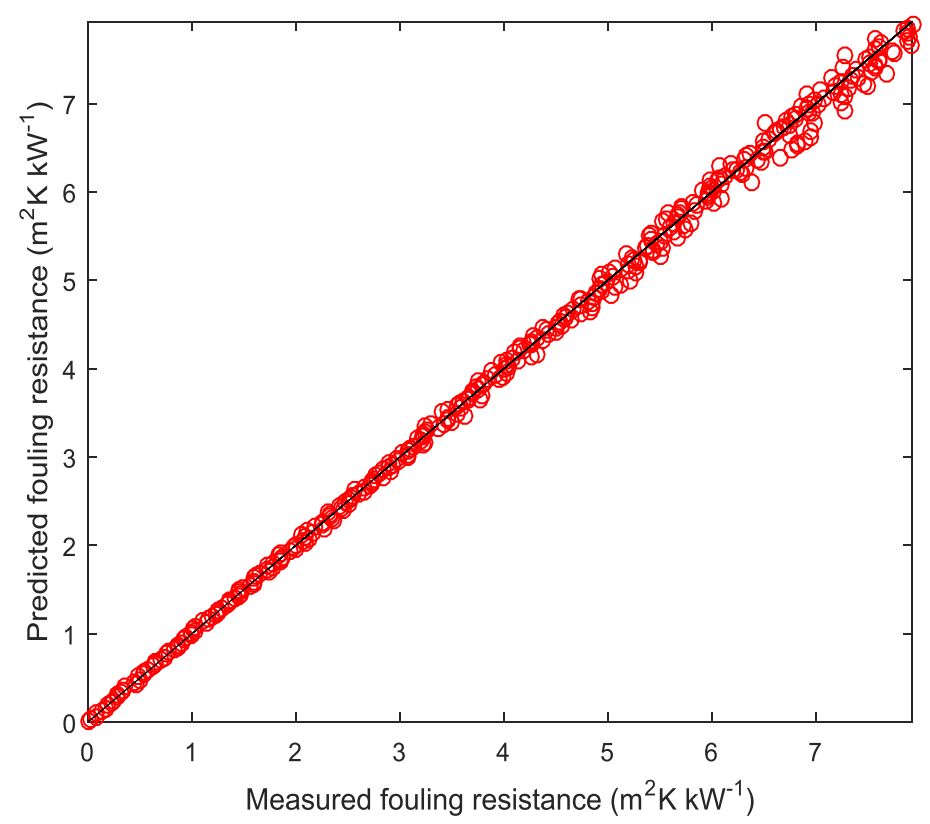

Figure 8: Parity plot for fouling resistance $R_{f}$ : Case 3

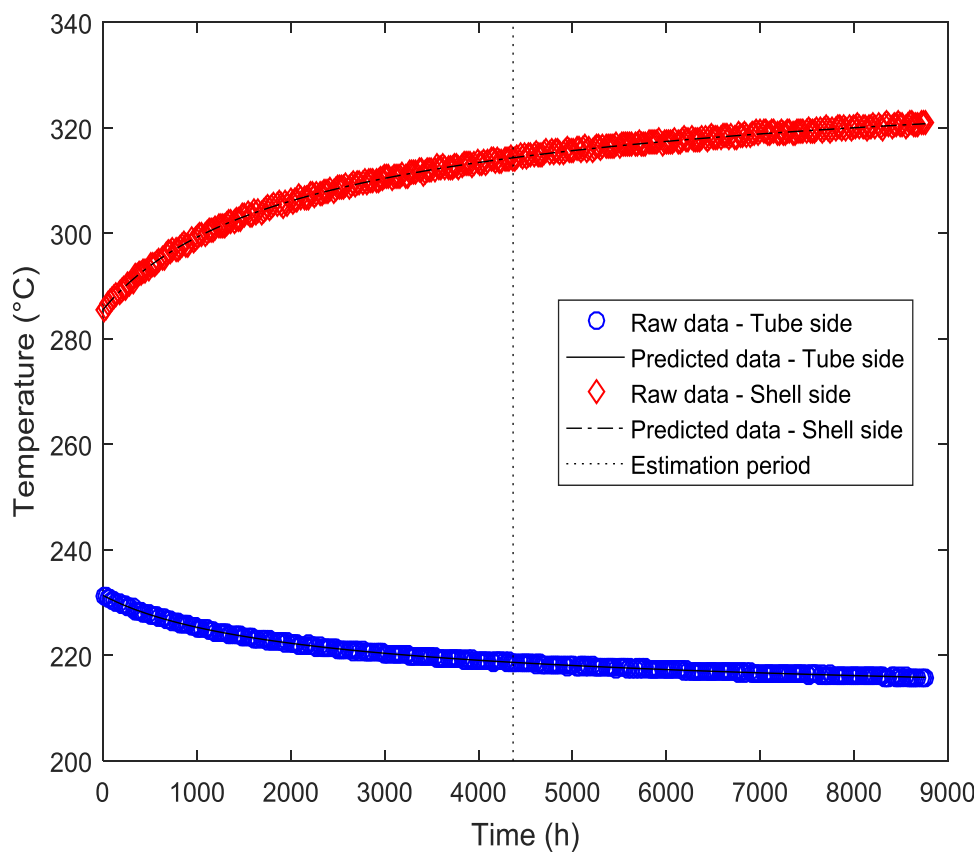

Figure 9: Simulated (synthetic data) and predicted (fitted model) outlet temperatures for tubeside and shell-side: Case 3 


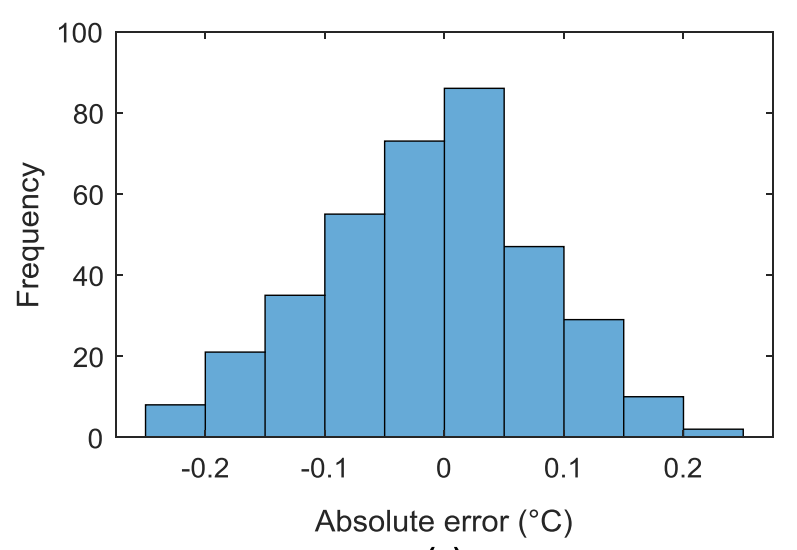

(a)

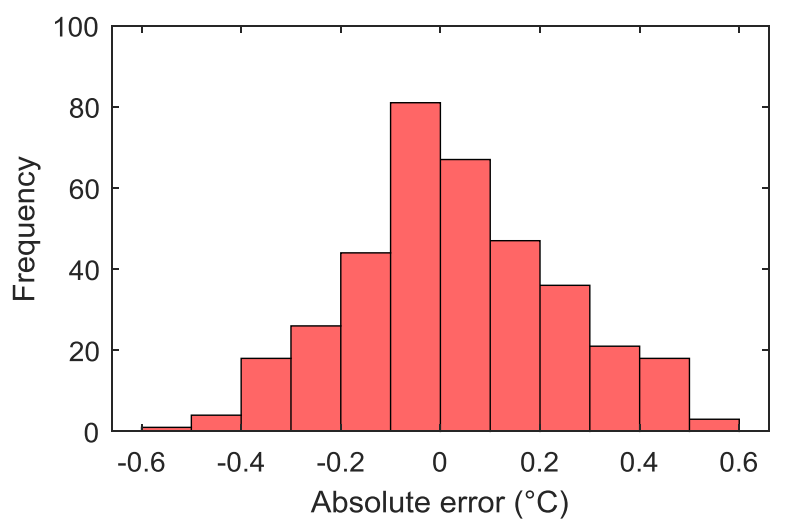

(b)

Figure 10: Absolute error for outlet temperature prediction of tube-side (a) and shell-side (b): Case 3

\subsection{Case 4: Data reconciliation and gross error detection and identification}

Identification and estimation of gross error locations and magnitudes are evaluated in this case study. That is, to find the presence of gross errors, along with the measurement(s) that contains said gross error(s) and finally, their numerical value. The statistical framework described in Section 3.2 is implemented in several subcases where a single error in different single measurements is deliberately added. The performance of the parameter estimation in each of these subcases is reported, along with an analysis of the accuracy of the gross error estimation method; that is, if the gross errors added in each subcase are correctly identified, located and estimated. Note that it is of great importance that all gross errors are correctly identified and estimated, as the accuracy of the parameter estimation depends on the level of reduction of random and gross errors, that is, how well the data are reconciled.

The presence of gross errors affects the measurement adjustments during reconciliation, as their impact differs from one measurement to the next, depending on the correlation between the measurements and the process constraints. In other words, if a single measurement is present in most of the process constraints, it is more likely that the presence of gross error will impact this measurement's adjustments during reconciliation in a higher level, compared to another 
measurement used in fewer constraints. This effect is known as the smearing effect ${ }^{12}$ and it needs to be accounted for, as it defines the minimum gross error magnitude for complete identification and estimation of such gross error.

For quantifying performance, the overall power function $(O P F)^{25}$ is used. This indicator is the ratio of the number of simulation trials where gross errors are perfectly identified, over the total number of simulations. The value of the overall power function is calculated using the whole set of simulation (one year with time steps of one day), when a given flow rate or temperature measurement has a bias. A successful solution for the gross error detection problem exists when the value of the OPF is equal to one ${ }^{28}$.

Different values of gross errors are added, based on the magnitude of standard deviation for each variable ( $\sigma_{m}$ and $\sigma_{T}$ respectively). Each gross error is assumed to be constant with time and their numeric values are added in two different measurements, separate and independently. Applying the approach described in Section 3.2 allows for identifying the presence, location and value of the gross errors. The cold stream inlet flow rate and the hot stream outlet temperature measurements are selected to have gross errors, giving a total of eight subcases. These measurements are used for visualizing the performance of the data reconciliation, when a gross error is present in a flow and temperature measurement. An outlet temperature is selected, as the value of this process variable directly depends on the severity of fouling deposition occurring in the heat exchanger. The effect of the presence and reconciliation of gross errors on the parameter estimation for fouling models is determined by the accuracy of the fitted parameters and the prediction capability of the fitted model, when predicting the outlet conditions of the heat exchanger (temperatures) after reconciling random and gross errors, as implemented in Case 3. The values of bias for each subcase are summarized in Table 11.

Table 11: Levels of gross errors added to data-set: Case 3

\begin{tabular}{|c|c|}
\hline Variable & Bias \\
\hline Flow rates & $3 \sigma_{m}, 6 \sigma_{m}, 9 \sigma_{m}$ and $12 \sigma_{m}$ \\
\hline Temperatures & $3 \sigma_{T}, 6 \sigma_{T}, 9 \sigma_{T}$ and $12 \sigma_{T}$ \\
\hline
\end{tabular}

The gross error identification and detection results for a single gross error in the cold stream inlet flow rate are shown in Figure 11. In this subcase, a gross error can be detected, identified and estimated with sufficient accuracy ( $O P F$ equal to 1.00) when the magnitude of the gross error has a value of at least $9 \sigma_{m}$. In terms of flow rate, the minimum magnitude for identification and estimation of a bias is $4.50 \mathrm{~kg} \mathrm{~s}^{-1}$. Any other gross error presenting a lower magnitude is not 
detected as bias (data-set passes the global test, see Equation (41)) and the data reconciliation algorithm adjusts this error as if it were a random error, which in some cases, leads to inaccurate reconciled measurements ${ }^{25}$.

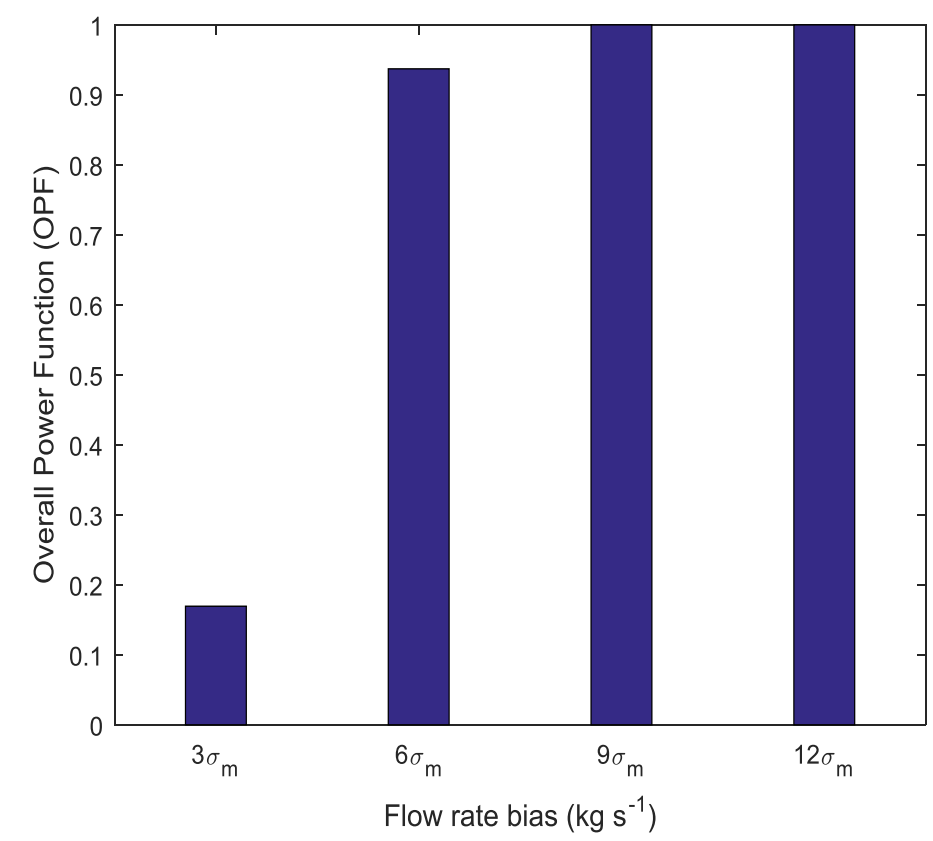

Figure 11: Minimum gross error magnitude estimation for cold stream input flow rate

Similar behavior is exhibited when there is a gross error located in the hot stream outlet temperature. The results for the minimum gross error value are illustrated in Figure 12. The value of the overall power function reaches 1.00 for a minimum bias magnitude of $9 \sigma_{T}$. In terms of temperature, the minimum of gross errors is estimated as $3.0^{\circ} \mathrm{C}$ approximately. As previously said, gross errors of less overall power than the estimated threshold are reconciled as random error.

Even if the presence of gross error is identified and mitigated resulting in an overall power function of 1.00, the alleviation of the effect of these gross errors in each measurement adjustment during data reconciliation does not reduce the entire value of the measurement error. Due to smearing effect, for relatively high gross errors values, such as those greater than $9 \sigma_{m}$ or $9 \sigma_{T}$, the set of reconciled measurements is different from the ones obtained for the same set, when no gross error is present, indicating the presence of smearing effect. This behavior is exhibited in the results of the parameter estimation. 


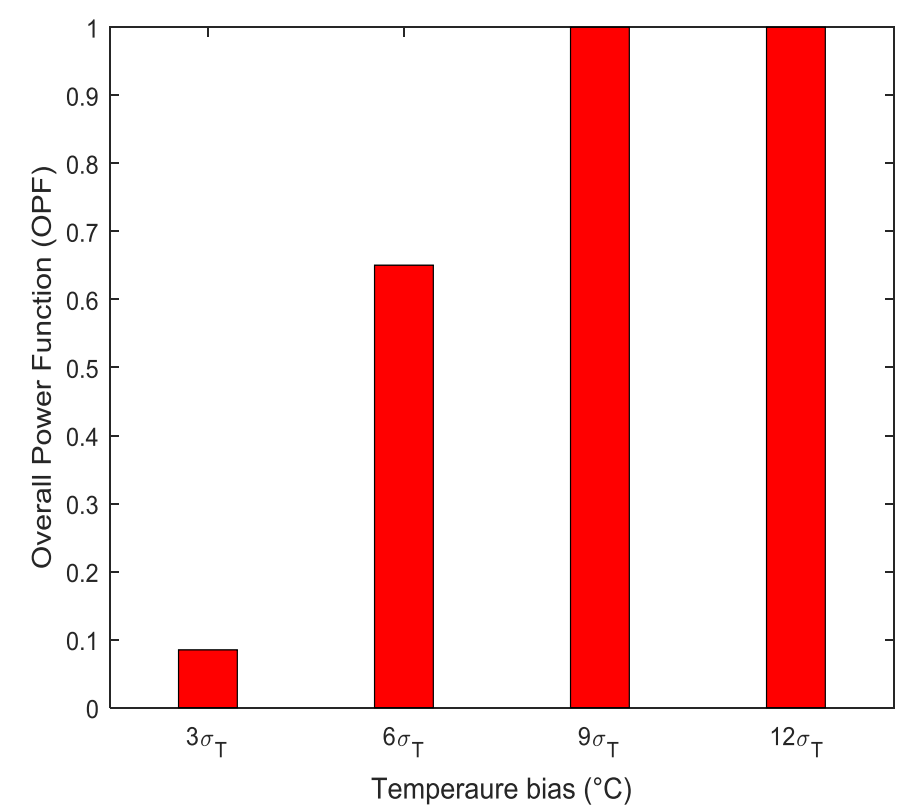

Figure 12: Minimum gross error magnitude estimation for hot stream outlet temperature

Results from the parameter estimation procedure for both subcases are shown in Table 12 and Table 13 respectively. The same four levels of gross error shown in Table 11 are used and the set of fouling model parameters, along with the value of RMSE are compared.

By comparing the results summarized in Table 12 and Table 13, it can be seen that the fouling model parameters are less accurate, as indicated by the values of RMSE, when a gross error is present in a temperature measurement.

Table 12: Estimated fouling model parameters for different levels of gross errors: cold stream input flow rate

\begin{tabular}{|c|c|c|c|c|c|}
\hline Parameter & Units & $\mathbf{3 \sigma}_{\boldsymbol{m}}$ & $\mathbf{6 \sigma}_{\boldsymbol{m}}$ & $\mathbf{9 \sigma}_{\boldsymbol{m}}$ & $\mathbf{1 2 \boldsymbol { \sigma } _ { \boldsymbol { m } }}$ \\
\hline$\hat{\alpha}_{1}$ & $\mathrm{~m}^{2} \mathrm{~K} \mathrm{~kW}^{-1} \mathrm{~h}^{-1}$ & $8.99 \mathrm{e}-07$ & $4.61 \mathrm{e}-06$ & $9.16 \mathrm{e}-07$ & $9.17 \mathrm{e}-07$ \\
\hline$\hat{\alpha}_{2}$ & $\mathrm{~m}^{2} \mathrm{~K} \mathrm{~kW}^{-1} \mathrm{~h}^{-1}$ & $5.08 \mathrm{e}+05$ & $5.34 \mathrm{e}+05$ & $5.03 \mathrm{e}+05$ & $5.03 \mathrm{e}+05$ \\
\hline$\hat{E}_{A}$ & $\mathrm{~kJ} \mathrm{~mol}^{-1}$ & 44.63 & 44.87 & 44.59 & 44.59 \\
\hline$\hat{\gamma}$ & $\mathrm{m}^{2} \mathrm{~K} \mathrm{~kW}^{-1} \mathrm{~h}^{-1}$ & $1.48 \mathrm{e}-08$ & $1.42 \mathrm{e}-08$ & $1.49 \mathrm{e}-08$ & $1.49 \mathrm{e}-08$ \\
\hline RMSE & -- & 0.044 & 0.044 & 0.044 & 0.044 \\
\hline
\end{tabular}

Table 13: Estimated fouling model parameters for different levels of gross errors: hot stream outlet temperature

\begin{tabular}{|c|c|c|c|c|c|}
\hline Parameter & Units & $\mathbf{3 \sigma}_{\boldsymbol{T}}$ & $\mathbf{6 \sigma}_{\boldsymbol{T}}$ & $\mathbf{9} \boldsymbol{\sigma}_{\boldsymbol{T}}$ & $\mathbf{1 2 \boldsymbol { \sigma } _ { \boldsymbol { T } }}$ \\
\hline$\hat{\alpha}_{1}$ & $\mathrm{~m}^{2} \mathrm{~K} \mathrm{~kW}^{-1} \mathrm{~h}^{-1}$ & $4.45 \mathrm{e}-07$ & $2.37 \mathrm{e}-06$ & $8.33 \mathrm{e}-07$ & $8.33 \mathrm{e}-07$ \\
\hline$\hat{\alpha}_{2}$ & $\mathrm{~m}^{2} \mathrm{~K} \mathrm{~kW}^{-1} \mathrm{~h}^{-1}$ & $9.69 \mathrm{e}+05$ & $1.16 \mathrm{e}+05$ & $7.49 \mathrm{e}+05$ & $7.49 \mathrm{e}+05$ \\
\hline$\widehat{E}_{A}$ & $\mathrm{~kJ} \mathrm{~mol}^{-1}$ & 47.19 & 48.01 & 46.26 & 46.26 \\
\hline$\hat{\gamma}$ & $\mathrm{m}^{2} \mathrm{~K} \mathrm{~kW}^{-1} \mathrm{~h}^{-1}$ & $1.49 \mathrm{e}-08$ & $1.48 \mathrm{e}-08$ & $1.48 \mathrm{e}-08$ & $1.48 \mathrm{e}-08$ \\
\hline RMSE & -- & 0.064 & 0.110 & 0.056 & 0.056 \\
\hline
\end{tabular}

The value of RMSE is lower for all levels of gross errors when this bias is in the flow rate measurement of the cold stream. Temperature measurements are related through nonlinear equations and, as a consequence, the quality of adjustments for reconciled values is lower than 
that of linear mass balance constraints. This effect is amplified when gross errors are considered. The smearing effect has a direct impact on the accuracy of measurement adjustments and decreases the accuracies of the reconciled estimates. As a result, higher values of the objective function for data reconciliation (Equation (32)) are obtained, leading to different values of fitted fouling model parameters, corresponding to higher values of RMSE. These differences are evident when comparing the values of RMSE in Table 10 and Table 13.

The goodness-of-fit results for fouling resistances, when minimum gross errors of $9 \sigma_{m}$ and $9 \sigma_{T}$ are added to the previously analyzed measurements (inlet cold flow rate and outlet hot temperature), are shown in Figure 13. Predictions for the heat exchanger's outlet conditions are illustrated in Figure 14. Absolute temperature differences between measured and predicted outlet temperatures for both subcases are shown in Figure 15. As mentioned, the presence of measurement error is more evident when gross errors affect a temperature measurement, where the outlet temperature at the hot stream is used as an example. The predicted fouling resistances when a flow rate bias is added are closer to their corresponding simulated values than those of when a temperature bias exists. As in Case 3, more scattering is found for higher values of fouling resistance. Nevertheless, the predictions for the outlet temperature in each subcase present good agreement, as indicated by the values of absolute temperature difference in Figure 15. 


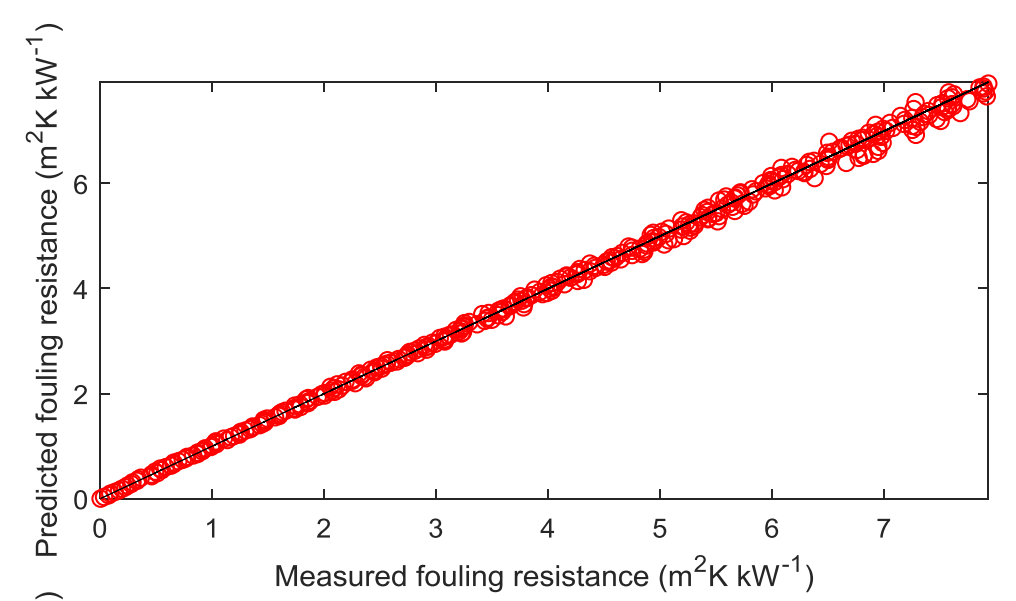

(a)

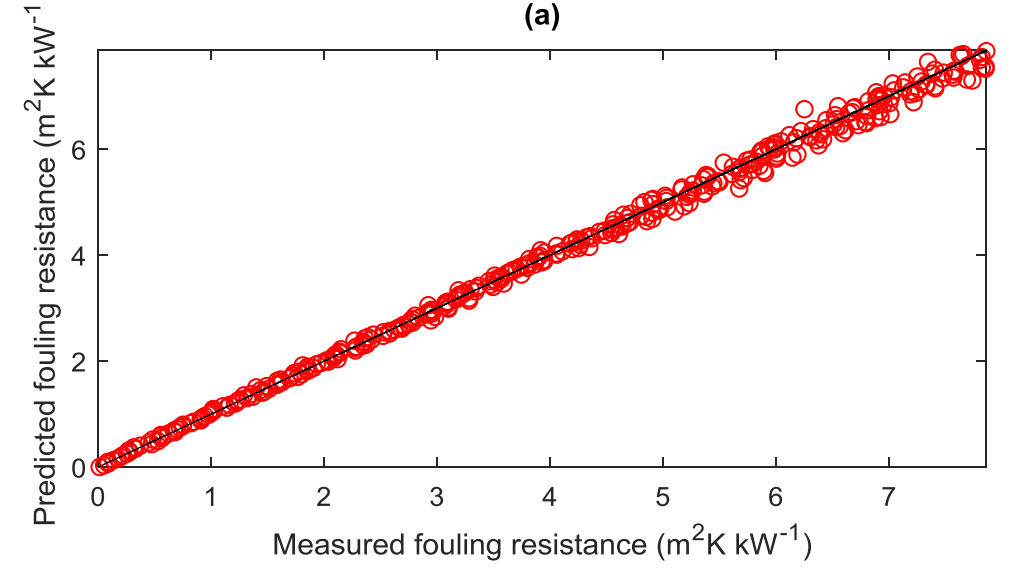

(b)

Figure 13: Parity plot for fouling resistance $R_{f}$ : Single gross error of magnitude $9 \sigma_{m}$ in inlet cold stream flow rate (a) and $9 \sigma_{T}$ in outlet hot stream temperature (b)

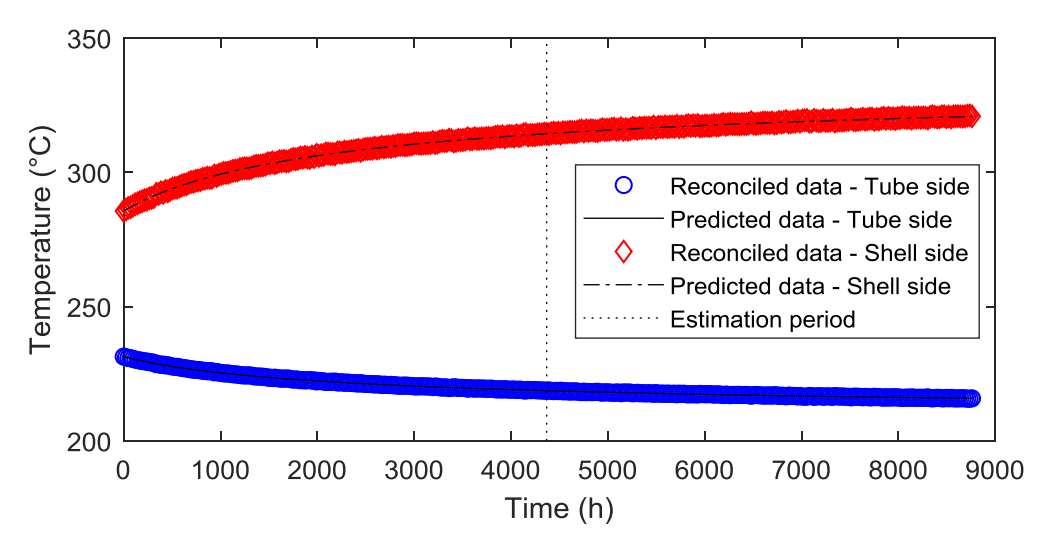

(a)

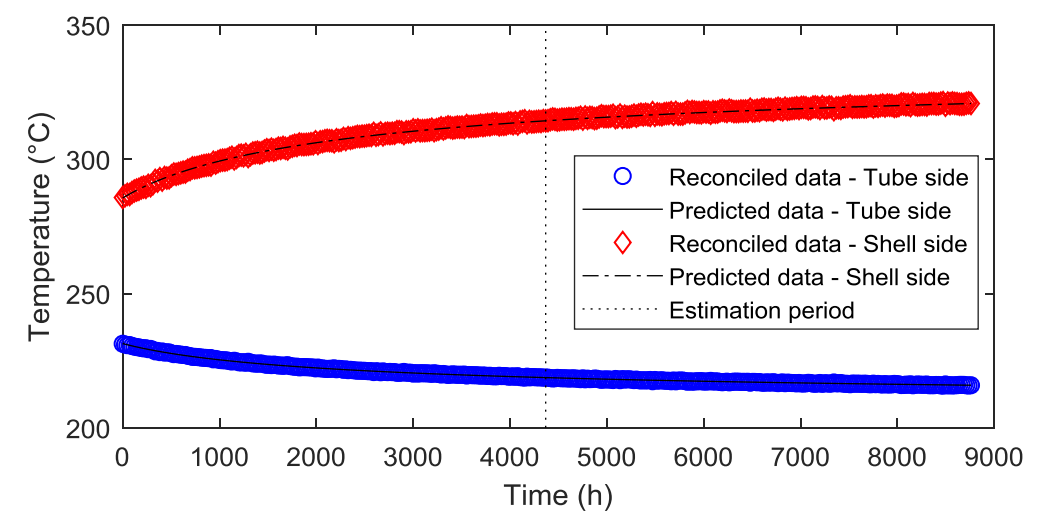

(b)

Figure 14: Shell-side and tube-side outlet temperatures using fitted fouling parameters for gross error magnitudes of $9 \sigma_{m}$ in cold stream inlet flow rate (a) and $9 \sigma_{T}$ in hot stream outlet temperature (b) 
The shell-side and tube-side outlet temperatures are accurately predicted as shown in Figure 14. There is a good agreement between the sets of values and the difference between predictions and adjusted measurements are judged to be acceptable, for both cases where a single gross error is found. The absolute errors in temperature prediction are shown in Figure 15. For both sides of the heat exchanger, a wider range of absolute error is calculated when gross errors are detected in temperature measurements, compared to the distribution of prediction-error when the gross error is located in flow rate measurements. The temperature differences are within the ranges of -0.23 and $0.23^{\circ} \mathrm{C}$ and -0.52 and $0.52^{\circ} \mathrm{C}$ for tube-side and shell-side respectively, when a flow rate bias is present. On the other hand, when the gross error is located in a temperature measurement, the absolute differences for tube-side and shell-side are in the ranges of -0.38 and $0.36{ }^{\circ} \mathrm{C}$, and -0.81 and $0.85^{\circ} \mathrm{C}$ respectively. These last values are slightly higher than the ones from Case 3. This fact is explained by the same reason mentioned in the analysis of Case 3, where the smearing effect and nonlinearities disturb the accuracy of each measurement adjustment.
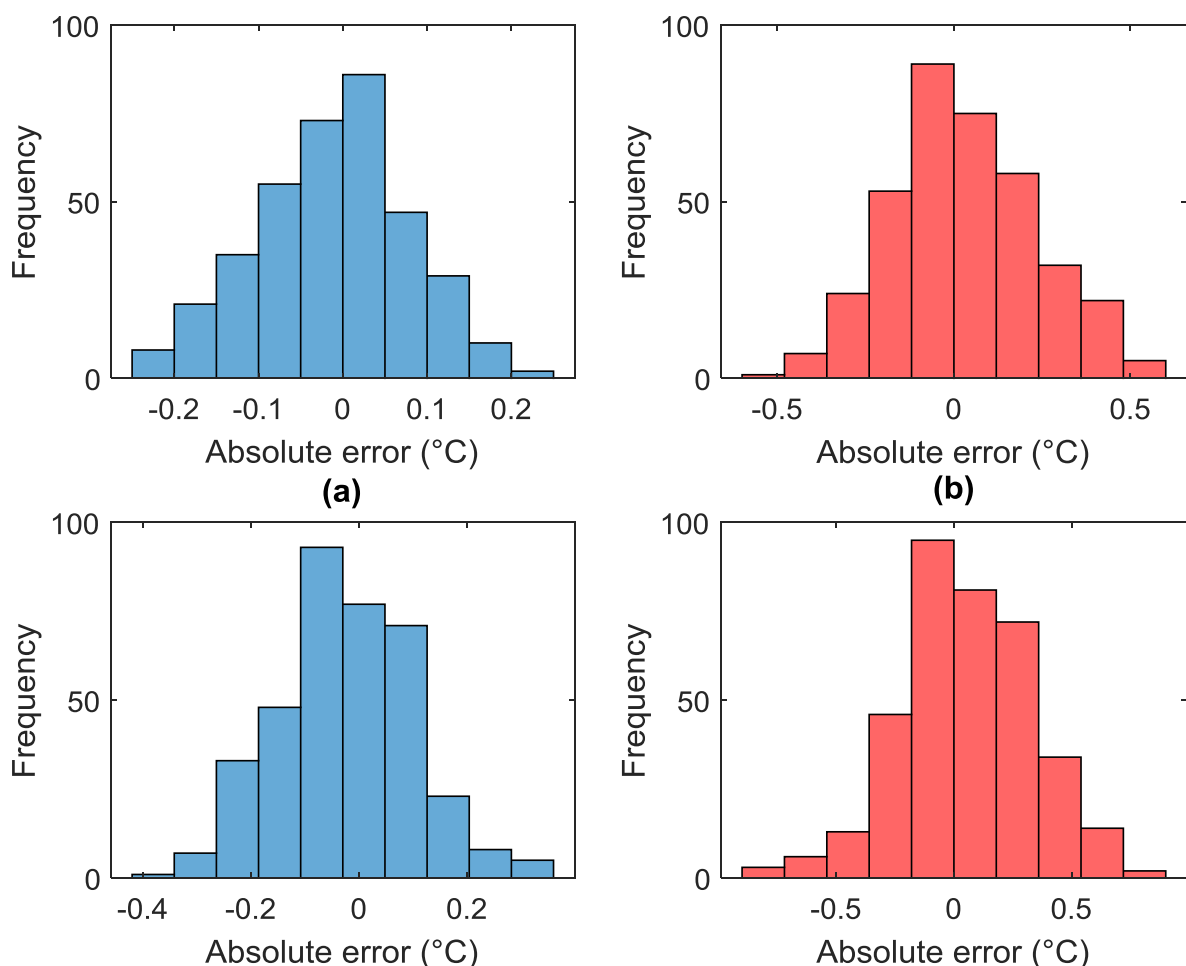

(c)

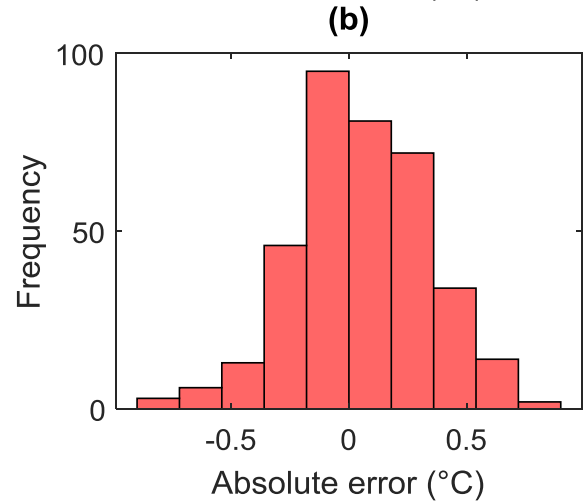

(d)

Figure 15: Absolute differences for predictions of tube-side (a) and shell-side (b) outlet temperatures for a gross error of $9 \sigma_{m}$ in cold stream flow rate and tube-side (c) and shell side (d) outlet temperatures for a gross error of $9 \sigma_{T}$ in hot stream outlet temperature

\section{Conclusions}

This work proposes an integrated methodology for determining fouling model parameters using data reconciliation and parametric fitting. It is shown that predictions for fouling resistance 
and heat exchanger conditions are also implemented using this methodology. The approach accounts for different types of geometries and stream allocations in the simulation and prediction strategies, as well as temperature-dependent physical properties when necessary. An advantage of this work is that it uses a pseudo-steady state formulation, which helps to reduce the complexity of calculations. Also, the updating of fouling resistance using fouling rate dynamic models helps to bring a more realistic perspective into the problem. In practice, measured data should be obtained from a fully-instrumented heat exchanger. However, to develop the approach and have confidence in the data sources, measurement error has been accounted for by adding random and systematic noise into the simulated data. Then, the data reconciliation and gross error detection algorithms have been applied to produce a usable (free-of-error) data set. A case study has been presented, where the effectiveness of the data reconciliation and gross error detection methods, along with the parameter estimation approach, were tested. Results showed good agreement for all cases. It has been shown that special attention is required when a gross error is located in any temperature measurement, as the smearing effect and the presence of gross errors become greater when higher levels of redundancy and nonlinearities are present.

The fitted models worked with accuracy in the case study, as it is evident from comparisons of fouling resistances and outlet temperatures of the heat exchangers. In terms of prediction errors, the maximum absolute difference in temperature predictions among the entire set of cases was $0.85^{\circ} \mathrm{C}$.

Different fouling rate models were used for the shell-side and tube-side of the heat exchanger. The overall fouling resistance was successfully split into these two contributions, attributing specific values to shell and tube-side fouling model parameters. This approach can only be taken when each fouling mechanism is known, or at least when there is enough information regarding operating conditions and fluid properties (for both sides), so the correct mechanism can be selected, based on up-to-date evidence concerning the most suitable fouling mechanism. The methodology developed in this work allows for flexibility as to the type of mechanism that should be chosen for a certain heat exchanger. Note that shell-side fouling is a complex process, and its study is limited at the moment. Therefore, it is of great importance to understand this phenomenon (shell-side fouling deposition) and address any new discovery to an integrated methodology such as the one presented in this work. 
The use of this approach can be extended to a fully-instrumented heat exchanger network, where fouling can occur on both sides of all heat exchangers, presenting different rate mechanisms. The advantage gained from accurately calculating fouling rate models can be further exploited by integrating this approach with existing methods for design, retrofit and optimization of cleaning schedules for heat exchangers and heat exchanger networks, for estimating more realistically any economic savings in capital, maintenance and energy costs. The effect of fouling in the hydraulic performance of heat exchangers and heat exchanger network, as well as the effect of missing measurements along the equipment is to be considered for future contributions, in order to reach the level of complexity of real processes and to increase the rigorousness of the modelling framework.

\section{Acknowledgments}

The authors gratefully acknowledge the Chilean National Commission for Scientific and Technological Research (CONICyT) for the financial support granted for the development of this work. 


\section{Nomenclature}

\begin{tabular}{|c|c|c|}
\hline Symbol & Definition & Units \\
\hline$A$ & Area & $\mathrm{m}^{2}$ \\
\hline$a b s_{T}$ & Absolute temperature difference for model prediction & ${ }^{\circ} \mathrm{C}$ \\
\hline$b_{x m}$ & Linearization term & -- \\
\hline$B_{\xi}$ & Bias location matrix & -- \\
\hline$c p$ & Heat capacity & $\mathrm{kJ} \mathrm{kg}^{-1 \circ} \mathrm{C}^{-1}$ \\
\hline$\overline{C P}$ & Mean capacity flow rate & $\mathrm{kJ}{ }^{\circ} \mathrm{C}^{-1}$ \\
\hline$C_{r}$ & Heat capacity flow rate ratio & -- \\
\hline$d_{i}$ & Tube inner diameter & $\mathrm{m}$ \\
\hline$d_{o}$ & Tube outer diameter & $\mathrm{m}$ \\
\hline$E_{A}$ & Activation energy & $\mathrm{kJ} \mathrm{mol}^{-1}$ \\
\hline $\operatorname{err}_{s d}$ & Relative error for reduction in standard deviation & -- \\
\hline$F_{L}$ & Leakage factor & -- \\
\hline$F_{p}$ & Pitch factor & -- \\
\hline$F_{S}$ & Correction factor shell side heat transfer coefficient & -- \\
\hline$g_{\xi}$ & Bias magnitude & $\mathrm{kg} \mathrm{s}^{-1}$ or ${ }^{\circ} \mathrm{C}$ \\
\hline$h$ & Local heat transfer coefficient & $\mathrm{kW} \mathrm{m}{ }^{-2}{ }^{\circ} \mathrm{C}^{-}$ \\
\hline$J_{x m}$ & Jacobian matrix & -- \\
\hline$k$ & Total number of time steps & -- \\
\hline$L$ & Length & $\mathrm{m}$ \\
\hline$m$ & Mass flow rate & $\mathrm{kg} \mathrm{s}^{-1}$ \\
\hline$n$ & Time step index & -- \\
\hline nshells & Number of shells & -- \\
\hline$N T U$ & Number of transfer units & -- \\
\hline$O P F$ & Overall power function & -- \\
\hline $\operatorname{Pr}$ & Prandtl number & -- \\
\hline$Q$ & Heat duty & $\mathrm{kW}$ \\
\hline$q_{\xi}$ & Vector of constraint residuals & -- \\
\hline$R e$ & Reynolds number & -- \\
\hline
\end{tabular}




$\begin{array}{lll}R_{f} & \text { Fouling resistance } & \mathrm{m}^{2}{ }^{\circ} \mathrm{C} \mathrm{kW}^{-1} \\ R_{g} & \text { Ideal gas constant } & \mathrm{kJ} \mathrm{mol}{ }^{-1}{ }^{\circ} \mathrm{C}^{-1} \\ \text { RMSE } & \text { Root mean square error } & - \\ r_{\xi} & \text { Random error magnitude } & \mathrm{kg} \mathrm{s}{ }^{-1} \text { or }{ }^{\circ} \mathrm{C} \\ T & \text { Temperature } & { }^{\circ} \mathrm{C} \\ U_{c} & \text { Clean overall heat transfer coefficient } & \mathrm{kW} \mathrm{m}{ }^{-2} \mathrm{C}^{-1} \\ U_{d} & \text { Fouled heat transfer coefficient } & \mathrm{kW} \mathrm{m}{ }^{-2}{ }^{\circ} \mathrm{C}^{-1} \\ x_{M} & \text { Measured magnitude } & \mathrm{kg} \mathrm{s}^{-1} \text { or }{ }^{\circ} \mathrm{C} \\ x_{R} & \text { True or reconciled magnitude } & \mathrm{kg} \mathrm{s}^{-1} \text { or }{ }^{\circ} \mathrm{C} \\ y_{c} & \text { Binary variable for NTU formulation } & -- \\ \Delta t & \text { Time step difference } & \mathrm{s} \\ \Delta T_{L M} & \text { Logarithmic mean temperature difference } & { }^{\circ} \mathrm{C}\end{array}$

\section{Greek}

$\begin{array}{lll}\alpha_{1} & \text { Particulate fouling rate term } & \mathrm{m}^{2 \circ} \mathrm{C} \mathrm{kW}^{-1} \mathrm{~h}^{-1} \\ \alpha_{2} & \text { Chemical reaction fouling deposition term } & \mathrm{m}^{2 \circ} \mathrm{C} \mathrm{kW}^{-1} \mathrm{~h}^{-1} \\ \gamma & \text { Chemical reaction fouling suppression term } & \mathrm{m}^{2 \circ} \mathrm{C} \mathrm{kW}^{-1} \mathrm{~h}^{-1} \\ \delta & \text { Level of significance } & -- \\ \varepsilon & \text { Thermal effectiveness } & -- \\ \varepsilon_{a} & \text { Thermal effectiveness for multiple shells heat exchangers } & -- \\ \lambda & \text { Thermal conductivity } & \mathrm{kW} \mathrm{m}{ }^{-1} \\ \mu & \text { Viscosity } & \mathrm{Pa} \mathrm{m} \\ \nu & \text { Degrees of freedom } & -- \\ \sigma & \text { Standard deviation } & \mathrm{kg} \mathrm{s}{ }^{-1} \text { or }{ }^{\circ} \mathrm{C} \\ \tau & \text { Test statistical for global test } & -- \\ \tau_{c} & \text { Threshold value for global test } & -- \\ \phi_{\xi} & \text { Constraint residuals covariance matrix } & -- \\ \psi & \text { Measurement error covariance matrix } & --\end{array}$

\section{Subscripts}

$\begin{array}{ll}c & \text { Cold stream } \\ h & \text { Hot stream }\end{array}$




$\begin{array}{ll}i & \text { Inlet } \\ m & \text { Mass flow rate measurement } \\ \text { mean } & \text { Mean value } \\ \text { min } & \text { Minimum } \\ \text { o } & \text { Outlet } \\ \text { shell } & \text { Shell side } \\ T & \text { Temperature measurement } \\ \text { tube } & \text { Tube side } \\ W & \text { Wall }\end{array}$

\section{Superscripts}

$\begin{array}{ll}\sim & \text { Fitted values } \\ \sim & \text { Normalized values } \\ \text { after } & \text { After data reconciliation } \\ \text { before } & \text { Before data reconciliation } \\ L & \text { Lower bound } \\ m s r & \text { Measured } \\ U & \text { Upper bound }\end{array}$




\section{References}

1. Bott, T. R., Fouling of heat exchangers. Elsevier Science B.V.: Amsterdam, 1995.

2. Rodriguez, C.; Smith, R., Optimization of operating conditions for mitigating fouling in heat exchanger networks. Chemical Engineering Research and Design 2007, 85, (6), 839 - 851.

3. Coletti, F.; Joshi, H. M.; Macchietto, S.; Hewitt, G. F., Chapter One: Introduction. In Crude Oil Fouling, Gulf Professional Publishing: Boston, 2015; pp 1-22.

4. Epstein, N., Thinking about heat transfer fouling: a 5x5 matrix. Heat Transfer Engineering 1983, 4, (1), 43-56.

5. Ishiyama, E. M.; Pugh, S. J.; Paterson, B.; Polley, G. T.; Kennedy, J.; Wilson, D. I., Management of crude preheat trains subject to fouling. Heat Transfer Engineering 2013, 34, (89), 692-701.

6. Watkinson, A. P., Deposition from crude oils in heat exchangers. Heat transfer engineering 2007, 28, (3), 177-184.

7. Wang, Y.; Yuan, Z.; Liang, Y.; Xie, Y.; Chen, X.; Li, X., A review of experimental measurement and prediction models of crude oil fouling rate in crude refinery preheat trains. Asia-Pacific Journal of Chemical Engineering 2015, 10, (4), 607-625.

8. Kern, D. Q.; Seaton, R. E., A theoretical analysis of thermal surface fouling. British Chemical Engineering 1959, 4, (5), 258-262.

9. Wilson, D.; Polley, G.; Pugh, S., Ten years of Ebert, Panchal and the 'threshold fouling' concept. 2005.

10. Jiang, X.; Liu, P.; Li, Z., Data reconciliation and gross error detection for operational data in power plants. Energy 2014, 75, 14-23.

11. Romagnoli, J. A.; Sanchez, M. C., Data processing and reconciliation for chemical process operations. Academic Press: San Diego, California, United States, 1999; Vol. 2.

12. Martini, A.; Coco, D.; Sorce, A.; Traverso, A.; Levorato, P., Gross error detection based on Serial Elimination: Applications to an industrial Gas Turbine. In ASME Turbo Expo 2014: Turbine Technical Conference and Exposition, Düsseldorf, 2014.

13. Diaz-Bejarano, E.; Coletti, F., Modelling shell side crude oil fouling in shell and tube heat exchangers. In Proceeding of International Conference of Heat Exchanger Fouling and Cleaning, Malayeri, M. R.; Müller, E. A.; Watkinson, A. P., Eds. Dublin, Ireland, 2015; pp 8188.

14. Ebert, W. A.; Panchal, C. B., Analysis of Exxon crude-oil-slip stream coking data. In Fouling Mitigation of Industrial Heat-Exchange Equipment, Begell House: 1995; pp 451-460.

15. Wang, Y.; Pan, M.; Bulatov, I.; Smith, R.; Kim, J.-K., Application of intensified heat transfer for the retrofit of heat exchanger network. Applied Energy 2012, 89, (1), 45-59.

16. Yeap, B. L.; Wilson, D. I.; Polley, G. T.; Pugh, S. J., Mitigation of crude oil refinery heat exchanger fouling through retrofits based on thermo-hydraulic fouling models. Chemical Engineering Research and Design 2004, 82, (1), 53-71.

17. Polley, G. T.; Wilson, D. I.; Pugh, S. J.; Petitjean, E., Extraction of crude oil fouling model parameters from plant exchanger monitoring. Heat transfer engineering 2007, 28, (3), 185-192.

18. Polley, G. T.; Wilson, D.; Yeap, B.; Pugh, S., Evaluation of laboratory crude oil threshold fouling data for application to refinery pre-heat trains. Applied Thermal Engineering 2002, 22, (7), 777-788.

19. Coletti, F.; Macchietto, S., A dynamic, distributed model of shell-and-tube heat exchangers undergoing crude oil fouling. Industrial \& Engineering Chemistry Research 2011, $50,(8), 4515-4533$. 
20. Costa, A. L. H.; Tavares, V. B. G.; Borges, J. L.; Queiroz, E. M.; Pessoa, F. L. P.; Liporace, F. d. S.; de Oliveira, S. G., Parameter estimation of fouling models in crude preheat trains. Heat Transfer Engineering 2013, 34, (8-9), 683-691.

21. Cao, E., Chapter 7: Thermal design of shell and tube heat exchangers. In Heat Transfer in Process Engineering, 1st ed.; Soda, T.; Smith, S. M.; Madru, J. K., Eds. McGraw Hill Professional: USA, 2009; pp 147-216.

22. de Oliveira Filho, L. O.; Queiroz, E. M.; Costa, A. L. H., A matrix approach for steadystate simulation of heat exchanger networks. Applied Thermal Engineering 2007, 27, (14-15), 2385-2393.

23. Bhatti, M. S.; Shah, R. K., Chapter 4: Turbulent and transition convective heat transfer in ducts. In Handbook of single-phase convective heat transfer, S., K.; R.K., S.; W., A., Eds. Wiley: New York, 1987.

24. Ayub, Z. H., A new chart method for evaluating single-phase shell side heat transfer coefficient in a single segmental shell and tube heat exchanger. Applied Thermal Engineering 2005, 25, 2412-2420.

25. Narasimhan, S.; Jordache, C., Data reconciliation and gross error detection: An intelligent use of process data. Gulf Professional Publishing: Houston, Texas, United States, 1999.

26. Edgar, T. F.; Himmelblau, D. M.; Lasdon, L. S., Optimization of Chemical Processes. McGraw-Hill: New York, United States, 2001.

27. Madron, F. V., A new approach to the identification of gross errors in chemical engineering measurements. Chemical Engineering Science 1985, 40, (10), 1855-1860.

28. Sánchez, M.; Romagnoli, J.; Jiang, Q.; Bagajewicz, M., Simultaneous estimation of biases and leaks in process plants. Computers \& Chemical Engineering 1999, 23, (7), 841-857.

29. Bagajewicz, M. J.; Jiang, Q., Gross error modeling and detection in plant linear dynamic reconciliation. Computers \& Chemical Engineering 1998, 22, (12), 1789-1809.

30. Goldberg, D. E., Genetic Algorithms in Search, Optimization and Machine Learning. Addison-Wesley Longman Publishing Co., Inc.: Reading, Massachusetts, 1989; p 372.

31. EngineeringToolbox Comparing Flowmeters.

https://www.engineeringtoolbox.com/flowmeter-selection-d_526.html (accessed 28th March 2019),

32. Thermocoupleinfo.com Thermocouple Accuracies

https://www.thermocoupleinfo.com/thermocouple-accuracies.htm (accessed 28th March 2019),

33. Ahmad, S.; Polley, G. T.; Petela, E. A. In Retrofit of Heat Exchanger Networks Subject to Pressure Drop Constraints, AIChE Spring Meeting, Houston, Texas, US, 1989; Houston, Texas, US, 1989.

Table of Contents (TOC)/ Abstract Graphic

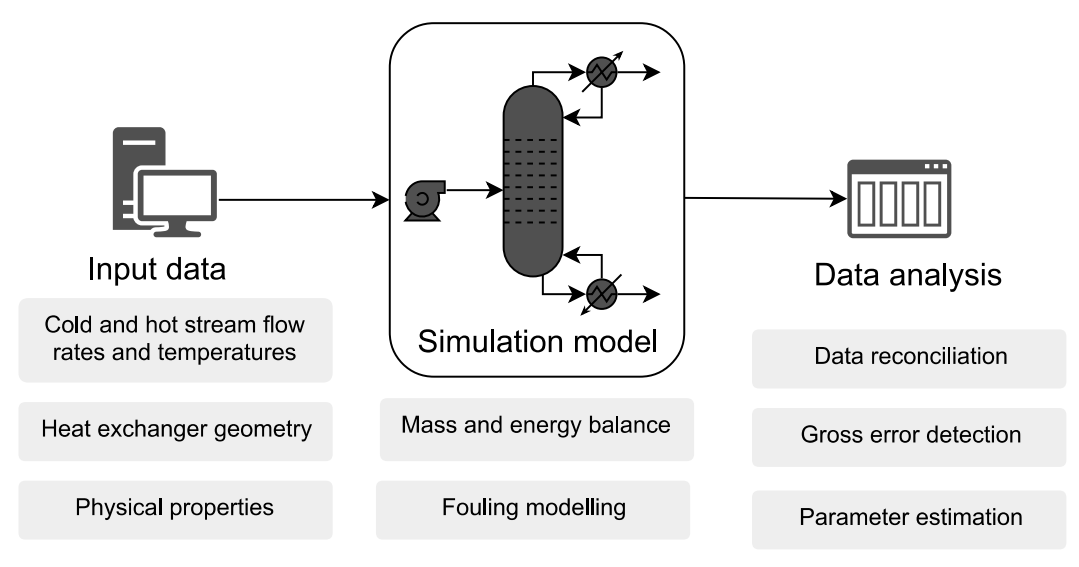

